Article

\title{
Analysis of susceptibility to slope movements in the environ- ment of road infrastructures. Models for obtaining predictive mapping applied to roads in the provinces of Malaga and Gra- nada (Spain)
}

\author{
María J. Perles-Rosellón ${ }^{1}$, Santiago Pardo-García², Juan F. Sortino-Barrionuevo³, Sergio Reyes-Corredera ${ }^{4}$ and Clau- \\ dio Puglisi ${ }^{5, *}$ \\ 1 Department of Geography. University of Málaga, Málaga, Spain; mjperles@uma.es \\ 2 Department of Geography. University of Málaga, Málaga, Spain; pardo@uma.es \\ 3 Department of Geography. University of Málaga, Málaga, Spain; francis.sortino@uma.es \\ 4 Geographical Analysis Research Group. Department of Geography. University of Málaga, Málaga, Spain; \\ sergioreyes@uma.es \\ 5 ENEA: Italian National Agency for Energy, New technologies and Environment-Roma, Via Anguillarese, 301, \\ Santa Maria di Galeria-00100, Roma, Italy; claudio.puglisi@enea.it \\ * Correspondence: mjperles@uma.es; Tel.: +34952133444
}

\begin{abstract}
This study addresses the peculiarities of the generation of slope movements in the context of road infrastructures and provide a predictive mapping of susceptibility to movements on slopes adjacent to road infrastructures (rockfalls). An inventory of slopes movements was mapped. From the development of the inventory of constant cases of mobilization that is used as a dependent variable, two statistical models can be obtained and compared for the same study area. One of them is based on the concept of frequency, whilst the other one is based on the application of a logistic regression. The results reveal the preponderant importance of lithology as a predictive variable, followed, at a considerable distance, by the slope gradient. Likewise, the importance of an unnatural and characteristic variable area of study, such as the presence of artificial cuts, is indicated as a causative factor. The results show a high degree of coincidence between the tendency of susceptibility predicted by the model, and the effective presence of empirical mobilization signs on the slopes, with Area Under Curve (AUC) values for Receiver Operating Characteristics (ROC) around 0.8 .
\end{abstract}

Keywords: Road infrastructures; risk; slope movements; cartography of susceptibility.

\section{Introduction}

The study of the propensity to slope movements on the slopes adjacent to linear road infrastructures (roads, railways, and other similar ones) requires a particular analysis of the susceptibility factors, since the high degree of anthropic alteration generates a mixed context between the natural and the artificial. In this situation, the conditions in which the predisposing factors to mobilization act can change their habitual behavior ([1]; [2]; [3]).

The elaboration of land susceptibility cartographies to mass movements has been broadly studied when they occur in a natural environment. On the contrary, work on susceptibility to mass movements in anthropized environments, has been less frequently treated. However, this is the area in which risk studies by mass movements acquire a more applied sense, given the strategic nature of the exposed elements (traffic, functional and economic activities affected by their interruption, and the infrastructure itself). Authors such as [4] have highlighted the importance of solving risk problems that affect infrastructures in tourist areas. [5] or [6], among others, highlight the importance of mass 
movements in the functioning of the city as a whole. Roadblocks and traffic stop as a result of slope movements are especially traumatic in peri-urban areas, since if mass movements happen after torrential rainfall, they do also occur simultaneously to floods of the urban area and/or overflows of urban and peri-urban channels. Because of that, the accessibility through alternative routes gets difficult, and the situation of crisis, emergency and risk for the population increases ([7]; [8]; [9]; [4]; [10]).

The identification of the points of the route with greater probability of being affected by mass movements allows decision makers to give priority to the most urgent preventive measures on each road, and thus, to directly contribute to reducing costs post-event, improving safety conditions and the sustainability of the infrastructure. The proposed model of susceptibility to mobilization that is presented here can be useful in infrastructures already built, but it can also be used in the project phase in order to simulate which would be the degree of danger for the alternative proposed paths. The subject of matter acquires a special interest and topicality in view of the promulgation of regulations that urge to the elaboration of specific risk maps for the especially sensitive environments of the so-called Critical Infrastructures.

The ultimate objective of this study is to propose different methodological strategies for the elaboration of maps of susceptibility to slope movements adjacent to road infrastructures, as well as to apply them and compare the results of the different predictive models proposed. Two alternative predictive models based on methods of varying degrees of complexity will be applied, and the predicted degrees of susceptibility will be validated with empirical data (evidence of movement collected in an inventory of slopes with detected signs of mobilization and fall). Therefore, the specific objectives addressed in this work are the following:

- To carry out a cartographic detailed inventory of the slopes adjacent to road infrastructures with effective signs of slope movements. This information will be used as a dependent variable in the susceptibility model based on a Weights-of-Evidence method.

- Prepare a predictive mapping of susceptibility to movement on slopes adjacent to road infrastructures. The predictive model is intended to include the particularities of the mixed environment (natural and artificial) in which the mobilization occurs, considering anthropic and natural controlling and triggering factors.

- To apply two types of methodological strategies of fundamentals and differentiated complexity for the deduction of the susceptibility model, based on the frequency (mode), and logistic regression.

- Test the predictive potential of susceptibility mapping in a validation experiment.

- To compare the results obtained through the different methods applied, and to conclude on their suitability for the analysis in the context of application.

\subsection{Background and state of art}

The International Association of Engineering Geology (IAEG), together with the UNESCO, was pioneered in the 70s of the twentieth century in the development of methodologies to assess and map the susceptibility to mass movements and geological risks. Since in 2006, the Thematic Strategy for the Protection of Soil of the European Union recognized rockslides as one of the eight major threats worldwide, systematic mapping studies on the susceptibility to gravitational movements have proliferated. A reference contribution in this line is the report "Guidelines for landslide susceptibility, hazard and risk zoning for land use planning" ([11]), in which the international working group on landslides JTC1 (Joint International Technical Committee on Landslides and Engineering Slopes), has attempted to standardize the evaluation and mapping of susceptibility and hazard by slope movements.

In Europe, many countries have developed national inventory landslide maps and, subsequently, susceptibility maps. To homogenize this large amount of data, in the framework of the European Soil Thematic Strategy, in 2007, the European Soil Bureau Network (ESBN) proposed a project for mapping the susceptibility to landslides on the 
European scale (i.e., 1: 1 million). This project has produced the preliminary European landslide susceptibility map (ELSUS 1000) ([12]). In Spain, the main contributions have been made by the Geological Survey of Spain (IGME), which has published inventory maps of rockslides since the $80 \mathrm{~s}$, and susceptibility maps at different scales of the different studied regions.

At the academic level, the development of susceptibility maps to mass movements has been widely addressed by researchers, although the object of study has preferably been the analysis of mass movements in natural environments, without considering the possible influence of anthropic factors. Some authors have addressed the problem by assessing the propagation distance ([13]; [14]) as well as the form of the potential transit and accumulation areas ([15]). Other authors have tried to adapt the methods to the climatic or physiographic contexts in which they are applied ([12]).

The mapping procedure has been traditionally treated by using geomorphological methods, and progressively, methodologies based on multivariate statistics and GIS techniques ([16]; [17]; [18]; [19]; [11]; [3]; [20]; [21]; among others) were applied. Other authors have contributed research in the evaluation of slope movements on rocky slopes. The techniques and methods of the geomechanical approach have been advancing since the contributions of [22], [23], or [24], up to recent proposals by [25] for quantitative hazard and risk assessment.

The proposed methodologies for assessing susceptibility at a detailed scale are very different and there is no general consensus among them. These methodologies are also conditioned by the amount and type of data available and by the scale of the study ([26]). Different approaches can be distinguished, such as those of heuristic overlap ([27]), statistical with a descriptive sense and supervised allocation of weights ([28] and [29]), or inferential, which implies a statistical use, e.g., univariate logistic regression ([30]), or multivariate. Authors such as [31] and [32] apply a deterministic approach, and others such as [33] and [19], apply different techniques to develop cartographies and perform a comparative analysis of their results.

In the present study, the application of a multivariate logistic regression is used as the basis of the methodology. This method has been widely used to perform susceptibility mapping for predictive purposes in different countries. ([34], [35]; [36], [37], [38]; [16]; [39]; [40]; [41]; [20]; [42]; [43]; [44]).

Linear infrastructures constitute a very sensitive environment not only because the structures themselves can be affected by mass movements, but also because the anthropic intervention alters the nature of the slope by varying the original level of susceptibility, and thus, modifying the conditions under which the determining and mobilizing activation factors act ([1]; [2]; [3]; [6]).

Previous studies of the behavior of mass movements when they occur nearby roads and road infrastructures can be cited ([45]; [46]; [47]; [40]; [48]; [29]; [19]; [8]). This line of research has been less frequently explored, despite its direct and applied interest, especially if it is about road infrastructures that articulate the peri-urban spaces of the city ([5]), on which a large part of the urban economic and demographic functioning depends ([7])

\section{Materials and Methods}

\subsection{Study area}

The proposed predictive procedure has been applied to roads of different categories in the provinces of Málaga and Granada (Andalusia, Spain). Altogether, a total of 563 slopes adjacent to the road have been mapped and analyzed, arranged in an overlying or underlying way along $76 \mathrm{~km}$ of road infrastructure. Specifically, three different sections of roads have been selected:

- Section 1. Road A-357, whose sector of study goes from the town of Casapalma to the junction of the A-357 with the A-367 (pk.14 to pk.48). This section runs for 34 $\mathrm{km}$ and is made up of 335 slopes adjacent to the road. 
- Section 2. Málaga ring road. This area of study goes entirely through the municipality of Málaga. Runs for $15,5 \mathrm{~km}$ and is made up of 190 slopes adjacent to the road.

- Section 3. Highway connecting Motril with Granada. This section extends for 26,5 $\mathrm{kms}$ and is made up of 38 slopes adjacent to the road.

The sections of road infrastructure selected for the study are spread over an area characterized by very steep gradients. From the geological point of view, it has a structural and tectonic complexity that grants great variability to the area, with juxtaposition and superposition of series of very different characteristics (Paleozoic schistose materials, Permo-Triassic series of conglomerates, plasters and clays, ultra-basic rocks (hazburguites and peridotites) and limestones and Jurassic dolomites, fundamentally). These materials, sometimes overlapped, have a high contrast in both the permeability and mechanical behavior of the rock, which increases the casuistry of susceptibility to movement. Susceptibility to mass movement on natural slopes close to the study area has been studied by [49] and [50]. The [51] has also published a generic cartography of natural risks in the province of Granada, which includes the treatment of the risk of mass movements.

The three study areas are located in a Mediterranean climate area. Concatenation of persistent rainy episodes with moderate intensity during several days are frequent, in which, at some point, rains of high intensity and with enough kinetic energy are produced, and they act as an activating factor of mobilization. This rainfall regime favors the phenomenon called multiple occurrence regional landslide events (MORLEs), where hundreds or thousands of surface rockslides happen roughly simultaneously within a determined area [52].

The peri-urban character of some of the infrastructures that constitute the area of analysis increases the likelihood of anthropic interventions in the environment, and thus, the existence of activating factors of the movement from an artificial origin, which increases the danger. On the other hand, these are areas of very high population vulnerability to slope movements. Effects over infrastructures in peri-urban areas produce a territorial dysfunctionality, which affects a high number of inhabitants and basic territorial functions such as the accessibility to housing and workplace, transport and the supply of goods, among the most prominent. The specific problems of mass movements in anthropized environments and close to road infrastructures have been studied in the context of the study area by [7] and [53].

All these characteristics show a high probability of mobilization in the selected areas, as well as a varied casuistry of causative factors, both of which have determined their selection. 


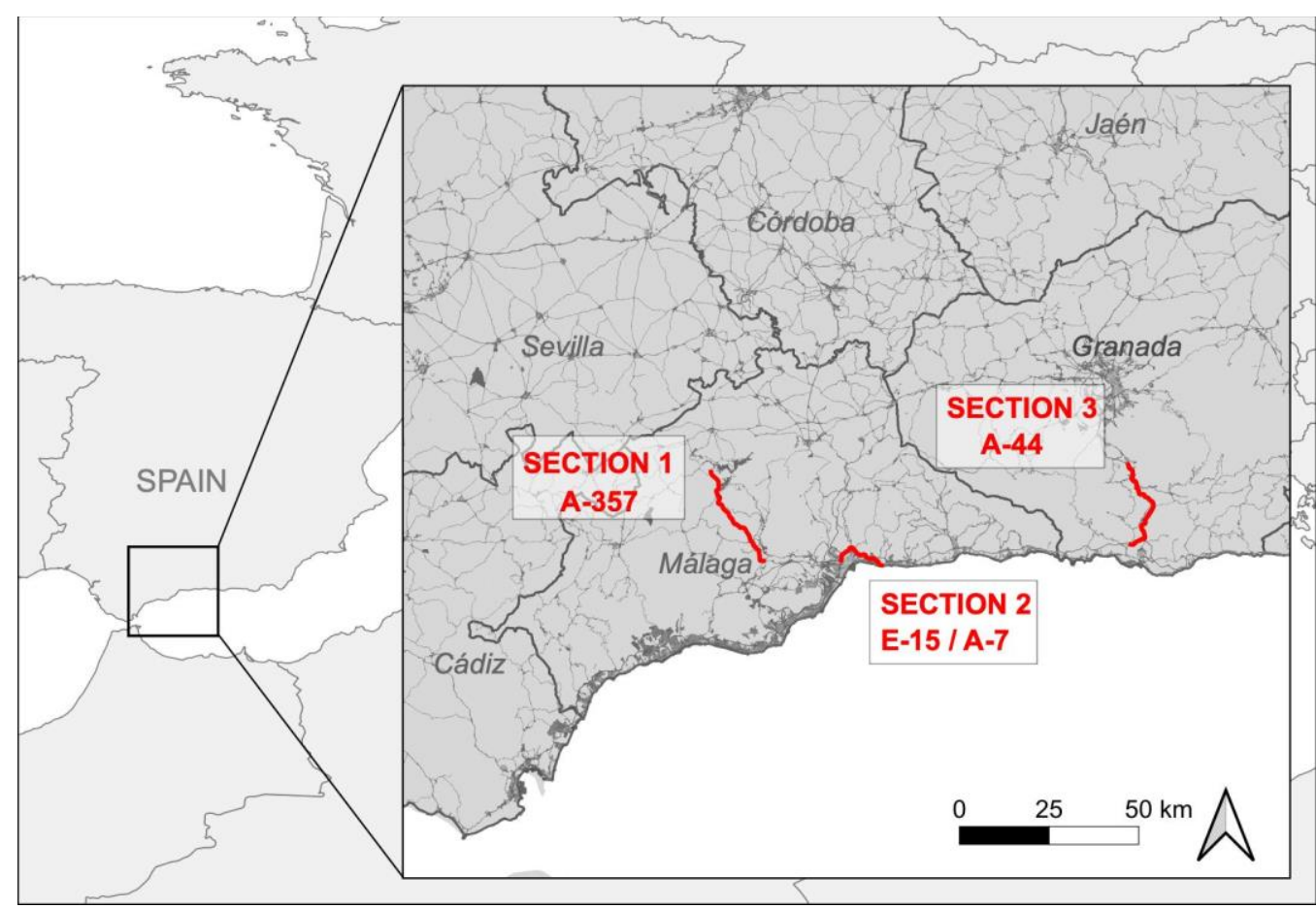

Figure 1. Location of the road sections selected as the study areas.

\subsection{Methodology}

The predictive methodology described in this study proposes that the probability of slope movements occurring within a slope was determined by comparing the predisposing and triggering factors of these slopes with those in areas where slope movements have occurred ([11]; [54], [55]). The methodology is based on a deterministic model, in which the susceptibility to land mobilization is calculated on the basis of the concurrence of factors predisposing to instability on each slope. As proposed by [38]; [42], among others, three steps have been carried out: the knowledge of slope movements type and distributions; the definition of a set of factors that can be used to predict the occurrence of a slope movement and the assessment of statistical relationships between the predisposing factors and the occurrence of slope movements.

Two different statistical procedures have been applied for the deduction of the predictive model. In this way, two predictive algorithms of varying degrees of complexity have been obtained, whose effectiveness as predictors has been compared against each other. The proposed models have been called WS (Weighted Summation), and BLR (Binomial Logistic Regression).

The slope has been used as a spatial and statistical unit of analysis to observe the concurrence in space of the predictor and dependent variables. All the slopes adjacent to road infrastructures have been delineated (slopes overlying the road and underlying or supporting it). Its cartographic delineation has been based on a DEM of $5 \times 5 \mathrm{~m}$ resolution (IGN) and orthophotos of the area (PNOA). For the delineation of the slopes, the automated delimitation of half basins flowing, contours, gradients, orientations, and shading false relief has been used. This semi-automated procedure has been used as initial support. The delimitation of slopes, as well as the inventory of movements on them, have been completed with a detailed work of photointerpretation and field work [53]. Through this semi-automated procedure, a total of 563 slopes of different sizes have been delimited. These set of slopes makes up the statistical universe of cases for the inventory of slope movements.

2.2.1. Development of the inventory of the slopes with signs of effective mobilization 
The effective verification of mobilization signs on the slopes of the study area has been used as a dependent variable, so these are the data that allow to validate the predictive model. The detected slope movements have been identified and classified according to the criteria of [56] and [57]. These are mostly stone falls with deposits on the shoulder, and, in other cases, falling and avalanche of blocks.

For the elaboration of the map of this variable, an inventory with the location of the slopes that show signs of mobilization have been carried out, based on the following sources and procedures:

- Field work, with the aim of observing the morphologies that indicate land mobilization (erosion or deposit) on the slopes.

- Compilation of information from the General Directorate of Roads (action reports) about maintenance activities related to the falling of material from the slope to the road or to the berm. Georeferencing press news related to traffic breaks due to slope movements.

- Presence in the study area of artificial interventions for slope control (breakwaters, retaining walls, berms), which were indicative of previous movements.

As a result of this task, a mapping of all the slopes movements adjacent to the roads has been obtained and classified according to whether if they show, or not, signs of mobilization. Slope movements type have been classified into two large groups: landslides and rock falls. The statistical model has been applied only to rockfall and small debris flow movements in this research. Slopes with landslides have been removed from the analysis since they constitute few cases and are caused by different predisposing factors. A total of 241 slopes have been selected for the statistical analysis of susceptibility to rockfalls.

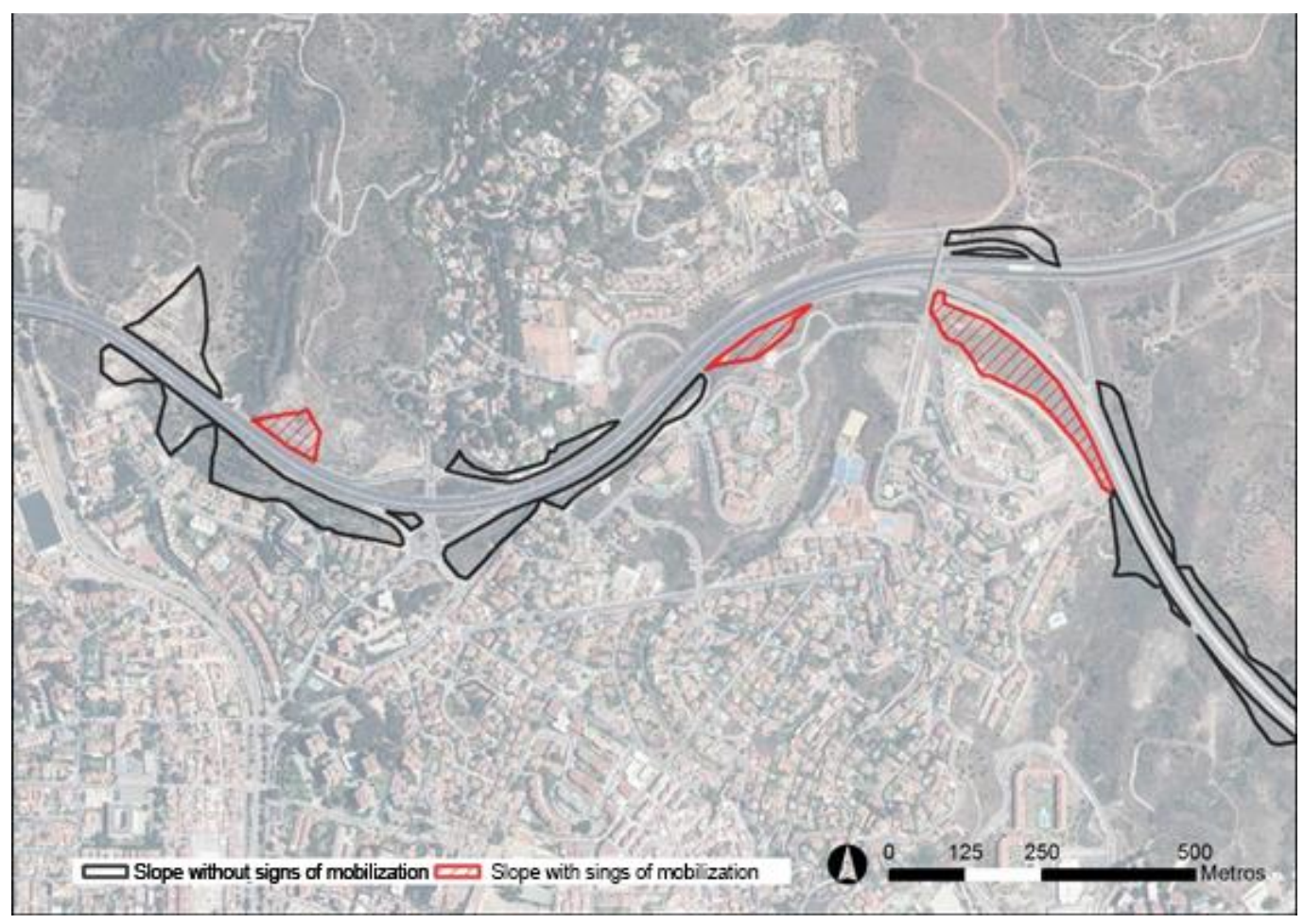

Figure 2. Slope map with empirical evidence of mobilization. (Detail).

The selection of predisposing factors has been based on bibliographic criteria ([58]), and particular attention has been granted when adding to the usual natural causes artificial factors that are characteristic of the anthropized environment of the roads, such as cuts, irrigation, extractive activity or clearing ([59]; [60]; [61]). No factors related to precipitation or seismicity have been included, as they are not spatially discriminatory when 
working at large-scale. In this sense, [41], observed the difficulty to relate precipitation with the concrete occurrence of the movement at a detailed scale.

The following are the variables that constitute the starting point of the analysis (Figure 3):

\begin{tabular}{|c|c|c|}
\hline \multirow{11}{*}{ 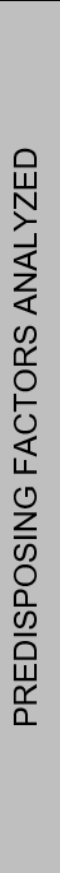 } & \multirow{6}{*}{$\begin{array}{l}\text { Selected factors in } \\
\text { the analysis }\end{array}$} & $\begin{array}{l}\text { Lithology slope stability (modified according to the degree of } \\
\text { alteration) }\end{array}$ \\
\hline & & $\begin{array}{l}\text { Internal heterogeneity of the lithological series (according to } \\
\text { its mechanical behavior) }\end{array}$ \\
\hline & & $\begin{array}{l}\text { Presence and type of lithological contacts (according to the } \\
\text { homogeneity degree of the lithologies in contact) }\end{array}$ \\
\hline & & Presence and type of tectonic discontinuity \\
\hline & & Slope gradient \\
\hline & & $\begin{array}{l}\text { Presence of artificial cuts on the slope (according to the } \\
\text { gradient and extension) }\end{array}$ \\
\hline & \multirow{3}{*}{$\begin{array}{c}\text { Factors excluded } \\
\text { from the analysis } \\
\text { due to the } \\
\text { insufficient number } \\
\text { of study cases }\end{array}$} & $\begin{array}{l}\text { Orientation of the strata prone to instability (relative position } \\
\text { of potential gliding planes with respect to the slope } \\
\text { orientation) }\end{array}$ \\
\hline & & Presence of active geomorphological forms \\
\hline & & Presence of water on the slope \\
\hline & \multirow{2}{*}{$\begin{array}{l}\text { Factors excluded } \\
\text { from the analysis } \\
\text { due to the lack of } \\
\text { correlation with the } \\
\text { dependent variable }\end{array}$} & Presence and type of vegetation \\
\hline & & $\begin{array}{l}\text { Signs of natural or artificial removal on the slope (linear } \\
\text { erosion, clearing, extractive activity and basal zapping by } \\
\text { water flow) }\end{array}$ \\
\hline
\end{tabular}

Figure 3. Predisposing factors to slope mobilization considered in the analysis.

2.2.2. Methodology of the predictive Model WS (Weighted Summation). Characterization of the combination of causative factors present on the mobilized slopes

The first step is based on identifying the pattern of causative factors present in the group of slopes that have already shown signs of rockfalls, and therefore, have empirical evidence of their greater susceptibility to mobilization. It is considered that the slopes on which the terrain is more likely to move (they have movement sings) would be those in which a greater number of instability conditions are concurrent, that is, a greater number of extreme values in the predisposing factors is reached. The concept of repetition of these unfavorable values in the set of fallen slopes (frequency of the extreme value in each predisposing variable), will be used to deduce the relative importance of each causative factor in the mobilization occurrence. Therefore, it is considered that the variables with a leading role in the pattern of susceptibility to the mobilization of the most unstable slopes (group of fallen slopes), are those in which the most extreme value is repeated a greater number of times. The falling probability of a slope $\left(\mathrm{p}_{\mathrm{i}}\right)$ is obtained by the following weighted sum, in which the coefficients $\beta_{\mathrm{n}}$ are the weights, and $\mathrm{x}$ the values assigned to each predictor variable:

$$
p_{i}=\beta_{1} \cdot x_{1}+\beta_{2} \cdot x_{2}+\cdots+\beta_{n} \cdot x_{n}
$$

As shown below, first, we have worked at the intravariable level, and, for each determining variable, severity intervals have been differentiated. In a later step, the intravariable analysis has allowed us to deduce the indicator coefficients of the relative importance of each predictor variable in the instability of the slope, and, finally, to construct a predictive algorithm.

2.2.2.1. Definition of intravariable intervals and assignment of scores to classes in the predictor variables 
For assigning the intravariable intervals and their corresponding scores, the following tasks have been carried out:

- The check-up of the intensity of the statistical relationship between each predisposing variable and the occurrence of slope mobilization.

- Considering the non-parametric character of most of the predictor variables, and the binary of the dependent one (fallen / not fallen slope), frequency histograms of the different degrees of the predictor variable path have been developed, as well as the percentages of falls that happen at each level in order to analyze the functions that relate each independent and dependent variable. Histograms have allowed us to establish the thresholds in which the cause-effect relationship presents more drastic variations, and to define intervals in the predictor variable to which a proportional score that runs from 0 to 1 has been assigned, being 1 the maximum susceptibility. The representative scores of zero and maximum susceptibility to movement in the predictor variables have been established from a common threshold, so that they are equivalent between some determining variables and others. The selected criteria have been:

o Negligible susceptibility: (Score $<=0.2$ ). Interval that includes all the values of the determining variables that coincide with cumulative percentages of slopes falling below $10 \%$.

o Maximum susceptibility: (Score $>=0.7$ ) Interval that includes the values of the predictor variable that coincide with a cumulative percentage of falls greater than $80 \%$ ).

The mobilization susceptibility scores deducted and assigned to each class or interval of the predisposing variables are summarized in the following table (Table 1):

Table 1. Mobilization susceptibility scores assigned to each class or interval of the predisposing variables. 


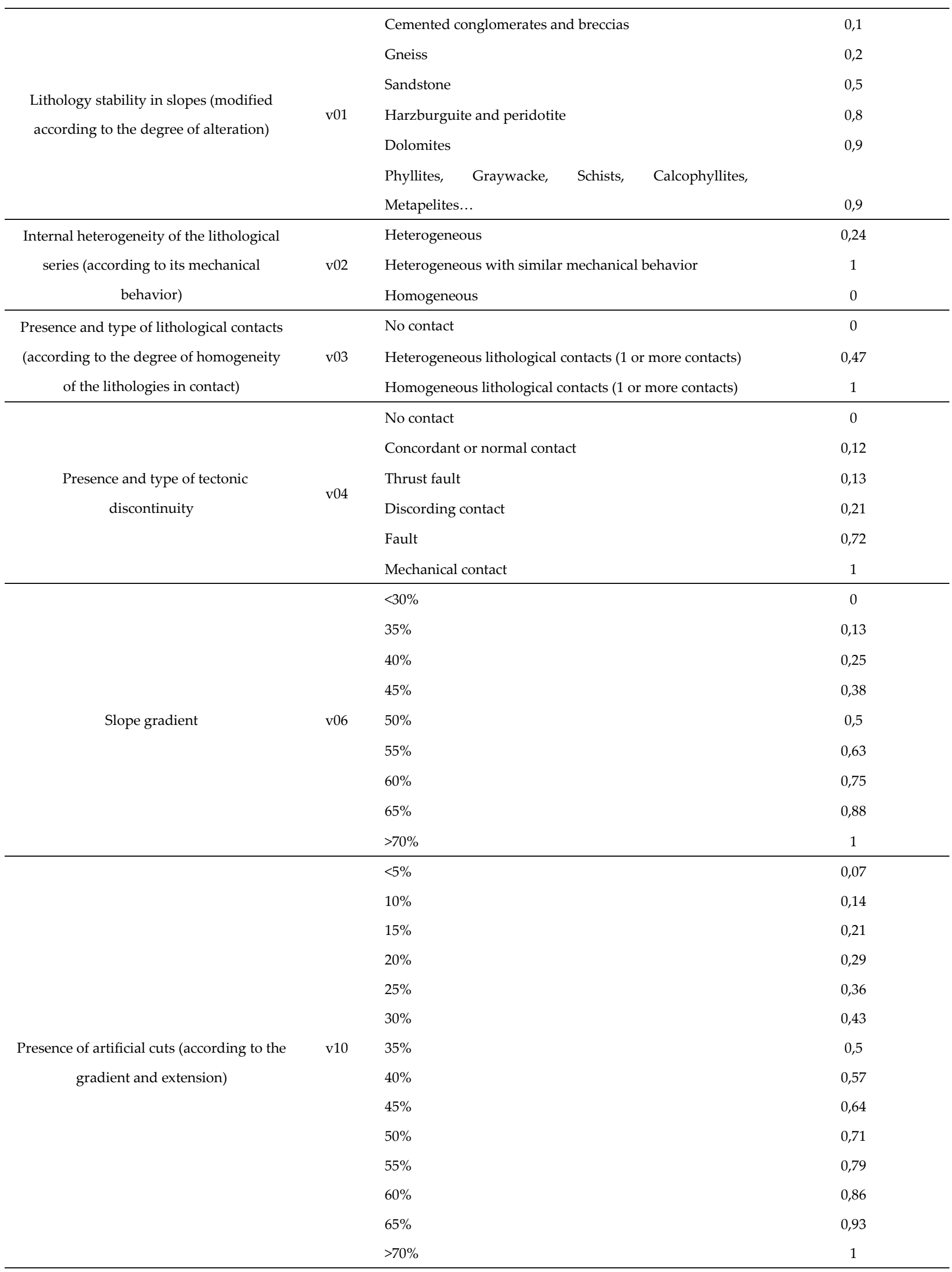


2.2.2.2. Definition of intravariable intervals and assignment of scores to classes in the predictor variables

It has been considered that the process of land falling is the result of a compensated association of the set of causative variables, so that the predictive model should be based on compensatory techniques ([62]). The procedure for assigning weighting coefficients has been conditioned by the non-parametric nature of the data.

For the estimation of the relative weight that each predictive variable has in the mobilization generation, the statistical analysis has focused on the group of slopes in which previous rockfalls have already been observed. The reasoning for deducing the weighting coefficients has been based on the calculation of the number of times in which the worst susceptibility value is repeated in each of the causative variables. It has been considered that the variables that most frequently repeat their worst susceptibility value are those that have the greatest incidence in the generation of the fall. At the same time, it has been verified that the worst susceptibility value appears poorly represented in each variable among the group of not fallen slopes (less than $20 \%$ ), which consolidates the research hypothesis.

From this reasoning, the following calculations have been made:

- The count of the number of times in which the range of greatest susceptibility of each predictive variable (scores greater than 0.7 ) is present in the group of fallen slopes.

-The sum of all the modes obtained for each variable, and standardization of their values to 1 (value of the total sum). This value becomes the weighting coefficient of the variable.

The formula used to obtain the weights by standardized variables is, in short, the following:

$$
\text { Variable weight }=\frac{\text { Frequency value } \geq 0.7 \text { in the variable }(\text { universe Falls })}{\text { Summaryvalues } \geq 0.7 \text { total of variables }(\text { universe Falls })}
$$

Once the predictor algorithm was calculated, it has been applied to all the slopes of the study area and the data of susceptibility to mobilization have been obtained. The resulting values have been classified in severity intervals for their cartographic representation. The intervals have been individualized based on the observation of the histogram of frequencies.

\subsubsection{Evaluation of the effectiveness of the WS model}

Once the predictive model was obtained through the WS method, the relationship between the measured values and those predicted by the algorithm has been evaluated through different analysis strategies. In addition to assessing the level of coincidence through percentages of success in the different severity intervals, a confusion matrix has been developed, which compares the measured and the predicted values, in order to assess the fitting of the prediction. The sensitivity value represents the ratio of positive values (value 1, fallen slopes) correctly predicted, whereas the specificity value refers to the negative values (value 0 , not fallen slopes). In both cases, the model is better fitted when high values in these concepts are obtained. The optimal threshold of probability of falling or not falling has also been calculated, based on a graph that shows the evolution of sensitivity and specificity, and its point of intersection (0.6 in this case).

A ROC (Receiver Operating Characteristic) curve has also been developed, which represents the percentage of correct positives that a logistic model predicts when the probability threshold is progressively lowered from 1 to 0 . A good model should indicate more measured 1 as positive and less measured 0 as positive as the threshold drops. Therefore, in a suitable model the curve should rise with a high gradient, indicating that the rate of 
correct positives (TPR, True Positive Ratio, $\mathrm{Y}$ axis) increases faster than the false positive ones (FPR. False Positive Ratio, $\mathrm{X}$ axis). For this reason, in a ROC curve, the larger the area under the curve (AUC), the better the predictive capacity of the model. The data obtained in the calibration exercise are shown in the results section.

2.2.3. Methodology for the development of the BLR predictive model (Binomial Logistic Regression)

2.2.3.1. Deduction of the predictive equation and evaluation of the effectiveness of the model

The second strategy utilized to make the map of susceptibility to rockfalls is based on a statistical model of logistic regression. The binomial logistic regression model is used when it is intended to predict the probability of occurrence of a particular event. It is a multivariate statistical method that allows to predict the presence or absence of a given event according to the values of a set of starting indicators. The binomial logistic regression allows us to deduce an equation that establishes the underlying mathematical relationship between a dependent dichotomous variable, and a set of independent predictor variables ([59]). For the analysis, variables of different nature and statistical expression (continuous or categorical, and with or without normal distribution) can be included.

In our case of study, the variable dependent on logistic regression acquires value 1 on those slopes collected in the inventory that have signs of mobilization, that is, that have experienced movements (falls).

The independent variables considered in the analysis (Model BLR.1) are shown below (Table 2):

Table 2. Susceptibility factors included in the BLR.1 model.

v01 - Lithology stability on slopes (modified according to the degree of alteration)

v02 - Internal heterogeneity of the lithological series (according to its

Independent variables mechanical behavior)

(model BLR.1) v03 - Presence and type of lithological contacts (according to the degree of homogeneity of the lithologies in contact)

v04 - Presence and type of tectonic discontinuity

v06 - Slope gradient

v10 - Presence of artificial cuts (according to the gradient and extension)

From these data, in a second phase, it has been decided to generate a new regression model by eliminating from the procedure the variables with less statistical significance (those with $\mathrm{p}>0.05$ ) (BLR.2 model), in order to observe whether the restriction clarifies the statistical procedure and improves the results. In this second iteration of the entire procedure, the independent variables used have been the following:

Table 3. Susceptibility factors included in the BLR.2 model.

$\begin{array}{cl} & \text { v01 - Lithology stability on slopes (modified according to the degree of } \\ & \text { alteration) } \\ \text { Independent variables } & \text { v03 - Presence and type of lithological contacts (according to degree of } \\ \text { (BLR.2 model) } & \text { homogeneity of the lithologies in contact) } \\ & \text { v06 - Slope gradient } \\ & \text { v10 - Presence of artificial cuts (according to the gradient and extension) }\end{array}$


The regression models have been generated using the "caret" package of $R$, adjusting them to binomial logistic regressions (method="glm",family=binomial(link="logit"). The cross-validation method $\mathrm{k}$-fold has been used for this (with 10 groups and iterations $(\mathrm{k}=10)$, choosing the model that maximizes the area under the ROC curve. The optimal threshold of probability cuts has been selected from cross-charts of sensitivity and specificity. From this data, the correctness of the estimation through a confusion matrix, the elaboration of the ROC curve, and the calculation of the area under the curve (AUC), which is the indicator of the goodness of the model as a predictor, have been verified.

For the two models generated (BLR.1 model and BLR.2 model) the $\beta$ coefficients for each variable, and their statistical significance have been calculated. These indicators have allowed us to discriminate the variables that have the most influence in the production of the mobilization, and to decide which ones to eliminate from the analysis in the second application of the model.

Once the coefficients have been obtained and their statistical significance has been analyzed, the probability of falling that they predict for each slope is then calculated. This information is added to the input data table, which makes its representation and analysis possible through GIS. The probability of falling is finally used to make maps of susceptibility to mobilization in a predictive way.

\section{Results and discussion}

The first result to comment on is the advantage that the topographic delimitation of slopes adjacent to the road offers for the analysis of causative factors. Using this procedure, the statistical unit is scaled to the slope, the basic geomorphological unit in which gravitational processes occur. In this way, the cause-effect relationships are directly related in each spatial unit. When larger spatial units are used, such as the basin ([64]), there are problems of generalization of the value of the causative factors that sometimes hinder the statistical relationship between cause and effect. The use of the slope as the basic unit of analysis also avoids other extrapolation problems associated with MAUP ([65]), which have been addressed by authors such as [66]; [67], [68] using different strategies.

\subsection{Results of the WS method: method based on the frequency of unfavorable conditions}

\subsubsection{Weighting coefficients and predictive algorithm obtained}

The weights obtained for each variable, once standardized, are the following (Table $4)$ :

Table 4. Weighting coefficients obtained for each predictor variable (WS Method)

\begin{tabular}{lccccccc}
\hline & \multicolumn{7}{c}{ Rockfall (variables) } \\
\cline { 2 - 8 } & $\begin{array}{c}\text { Litho } \\
(\mathrm{v} 01)\end{array}$ & $\begin{array}{c}\text { Slope } \\
(\mathrm{v} 06)\end{array}$ & IntHet (v02) & $\begin{array}{c}\text { ArtSlo } \\
(\mathrm{v} 10)\end{array}$ & $\begin{array}{c}\text { LithoCon } \\
(\mathrm{v} 03)\end{array}$ & $\begin{array}{c}\text { TectDisc } \\
\text { (v04) }\end{array}$ & TOTAL \\
\hline Count $(>=0,7)$ & 48 & 40 & 30 & 25 & 20 & 16 & 179 \\
\hline $\begin{array}{l}\text { Percentage with } \\
\text { respect to 49 FALLS }\end{array}$ & 0,98 & 0,82 & 0,61 & 0,51 & 0,41 & 0,33 & 3,66 \\
\hline Weighing & 0,27 & 0,22 & 0,17 & 0,14 & 0,11 & 0,09 & 1,00 \\
\hline
\end{tabular}


The algorithm has been calculated from 49 fallen slopes and its application has been extended to the rest of the slopes that make up the group of non-fallen slopes, which is composed of 241 study cases. As can be seen in Figure 4, the results obtained through the WS method show that the most influential variables in the generation of the instability of the tested slopes are, in this order, the lithology (0.27), the gradients $(0.22)$, and the internal heterogeneity of the lithological series $(0.17)$, followed by the presence of embankments on slope (0.14), and finally, with a much smaller participation in the process, by the presence of lithological contacts (0.11) and the presence of tectonic discontinuity (0.09). Lithology and weathering degree and spacing have been identified by different authors as key factors in the generation of falls. ([69]; [70] and [71], among others). These authors also highlight the orientation of discontinuities as a predisposing factor. This variable, although it was included in the initial set of predisposing factors to fall, has not been included in the statistical analysis due to the difficulty in identifying it on the slopes of the study area. Few cases have this information, so they are not statistically representative.

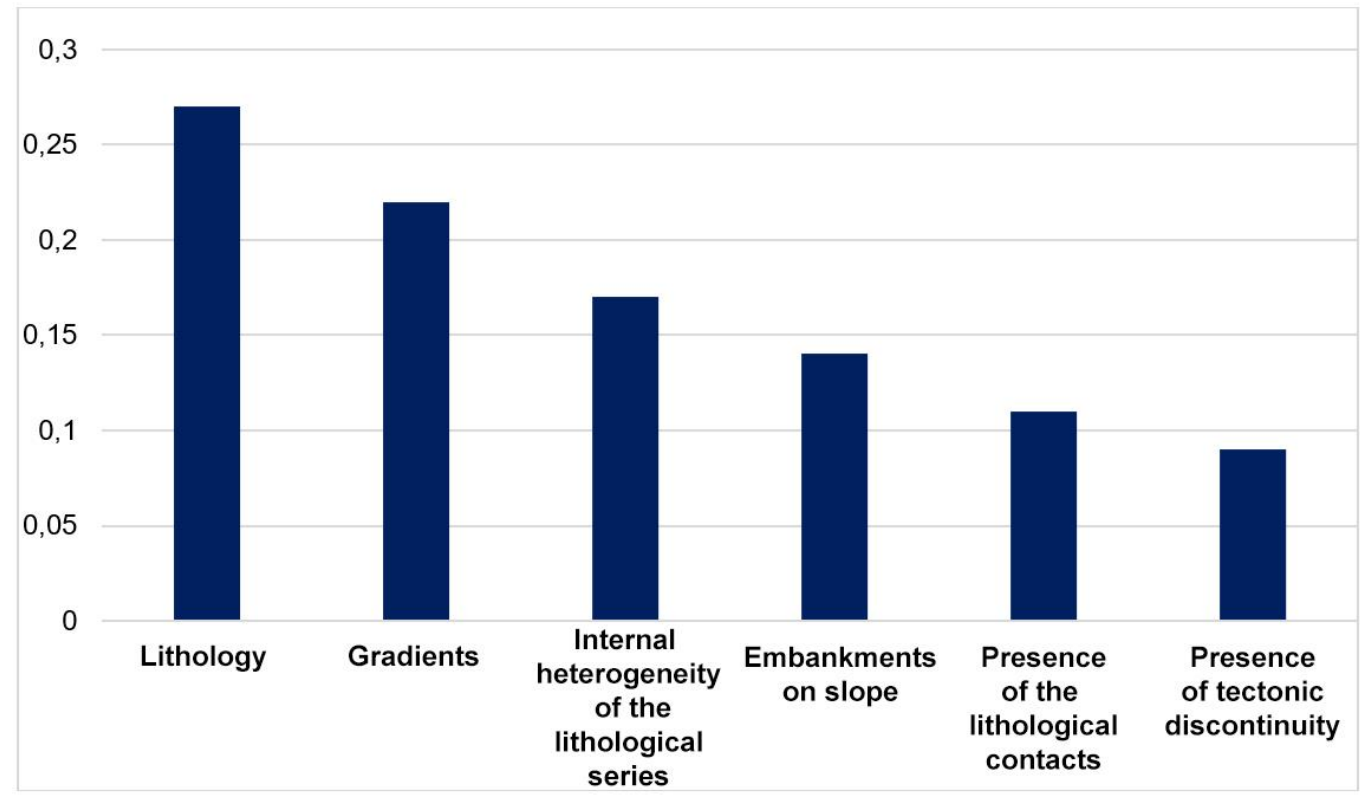

Figure 4. Weighting coefficients obtained for each predictor variable (WS Method).

From this data, the final predictive algorithm obtained is set as a weighted linear summation, in the following terms:

\section{Susceptibility to rockfalls $=$ Litho $^{*} 0,27+$ Grad $^{*} 0,22+$ IntHet $^{*} 0,17+$ EmbSlo$^{*} 0,14+$ LithoCon*0,11 + TectDisc*0,09}

The algorithm has finally been used to generate predictive maps of susceptibility to rockfalls. Representative intervals have been assigned from the observation of the frequency histogram. Figure 5 shows an example of cartographic prediction for the study area (section 1). 


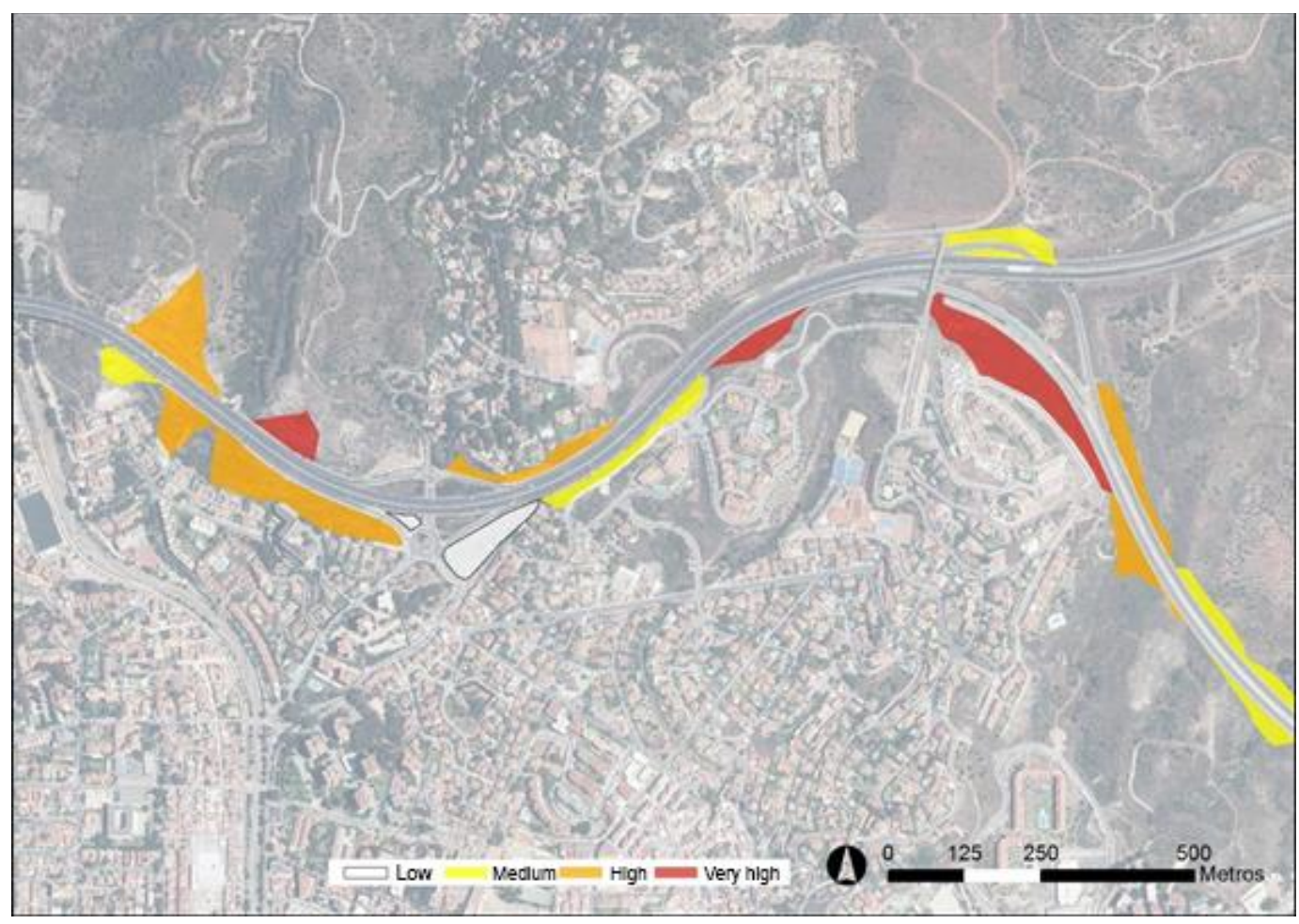

Figure 5. Map of susceptibility to slope rockfalls according to the WS predictive model.

3.1.2. Evaluation of the predictive capacity of the WS model

3.1.2.1. Matching predictive mapping with the inventory map of the mobilized slopes

The percentage of coincidence between the predictive cartography obtained with respect to the inventory-map of rockfalls observed on slopes has been tested. As can be seen in Table 5, the degree of coincidence between the slopes with empirical rockfalls, and those cataloged by the predictive model at the high and very high levels of susceptibility, stands at $82 \%$ of the cases. It should be noted that the predictive model has not registered cases at the low threshold, and it highlights that there is only $18 \%$ of the cases that are represented with the medium values.

Table 5. Degree of coincidence between slopes with observed rockfalls and those listed by the model.

\begin{tabular}{cccccc}
\hline & LOW & MEDIUM & HIGH & VERY HIGH \\
\hline Interval & $<0.35$ & 0.35 to $<0.6$ & 0.6 to $<0.8$ & $>=0.8$ & TOTA \\
\hline Fallen slopes & 0 & 9 & 27 & 13 & 49 \\
\hline Percentage of fallen slopes & 0 & 18.37 & 55.10 & 26.53 \\
predicted by the WS Model & & & & 100 \\
\hline
\end{tabular}




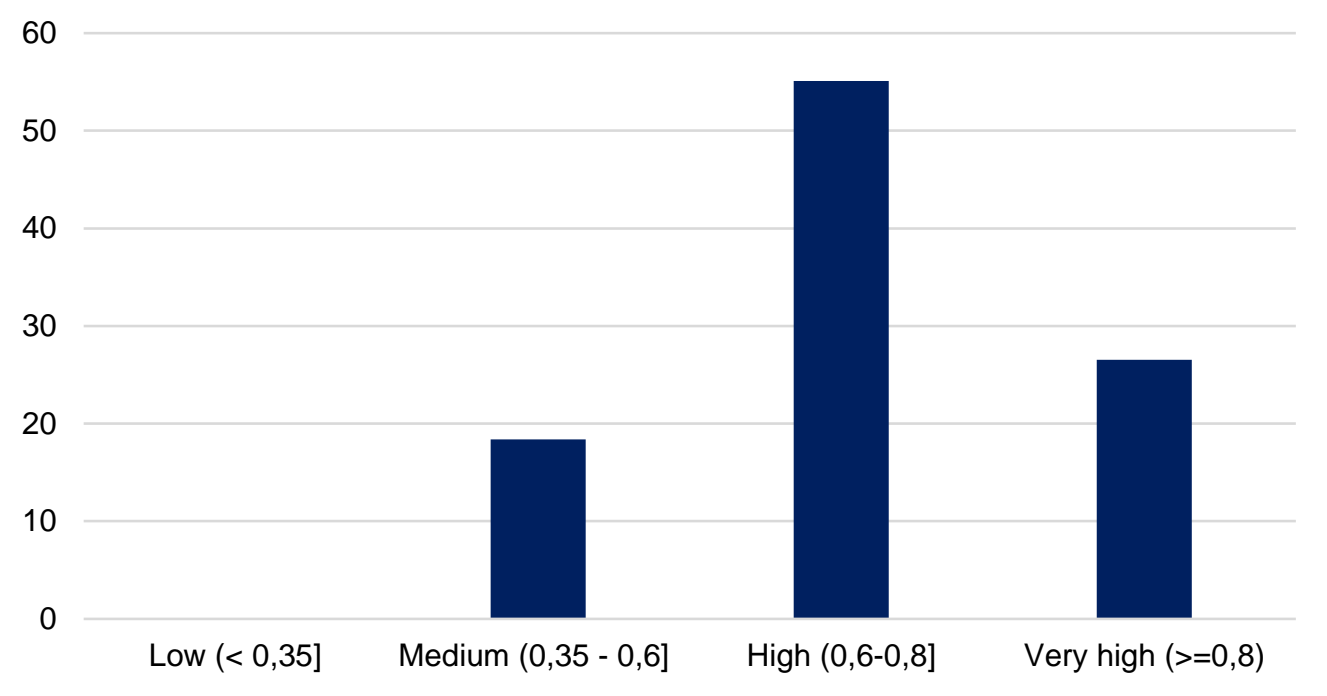

Figure 6. Percentage of fallen slopes in each prediction interval (WS model).

Below, the simulated data by the predictive model for all the slopes, and their corresponding proportion of the intervals of susceptibility likelihood are shown (Table 6):

Table 6. Simulated data by the predictive model for the selected slopes.

\begin{tabular}{cccccc}
\hline \multicolumn{5}{c}{ ROCKFALLS (SIMULATED SLOPES) } \\
\hline LOW & MEDIUM & HIGH & VERY HIGH \\
\hline Interval & $<0.35$ & 0.35 to $<0.6$ & 0.6 to $<0.8$ & $>=0.8$ & TOTAL \\
\hline Simulated & 0 & 9 & 27 & 13 & 49 \\
\hline (\%) Simulated & 0 & 18.37 & 55.10 & 26.53 & 100 \\
\hline
\end{tabular}

As can be seen, simulated cases for the very high category represent $7 \%$ of the total. The simulation proposed by this algorithm indicates that $60 \%$ of the slopes have a low probability of rockfalls (low and medium intervals), while $40 \%$ have a "high" or "very high" probability of causing rockfalls. More restrictively, only $7 \%$ of the cases have been identified with "very high" probability of falling (Figure 7).

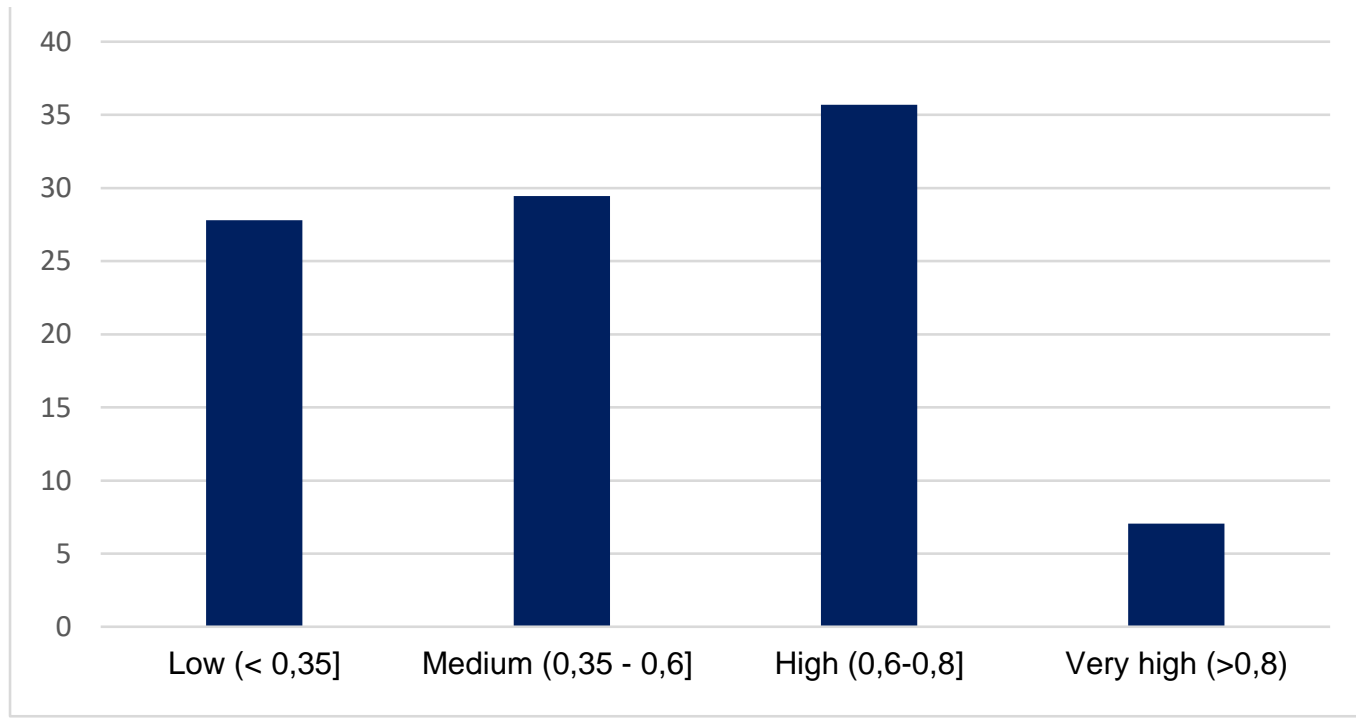

Figure 7. Percentage of fallen slopes in each prediction interval (WS model). 
To confirm the validity of the predictive model, a confusion matrix and a ROC curve with sensitivity and specificity values have been developed. The probability threshold for considering a slope as fallen has been set at 0.6 , a value that simultaneously optimizes the sensitivity and specificity of the model. As can be seen in Figure 8, the gradient of the ROC curve and the value of the Area Under the Curve (AUC) parameter, reveal a high degree of correspondence between the observed and the predicted values (AUC $=0.84$ ), and a good evolution of the ratio of correct positives and correct negatives of the prediction. All these indicators allowed to attribute a high predictive reliability to the WS model.

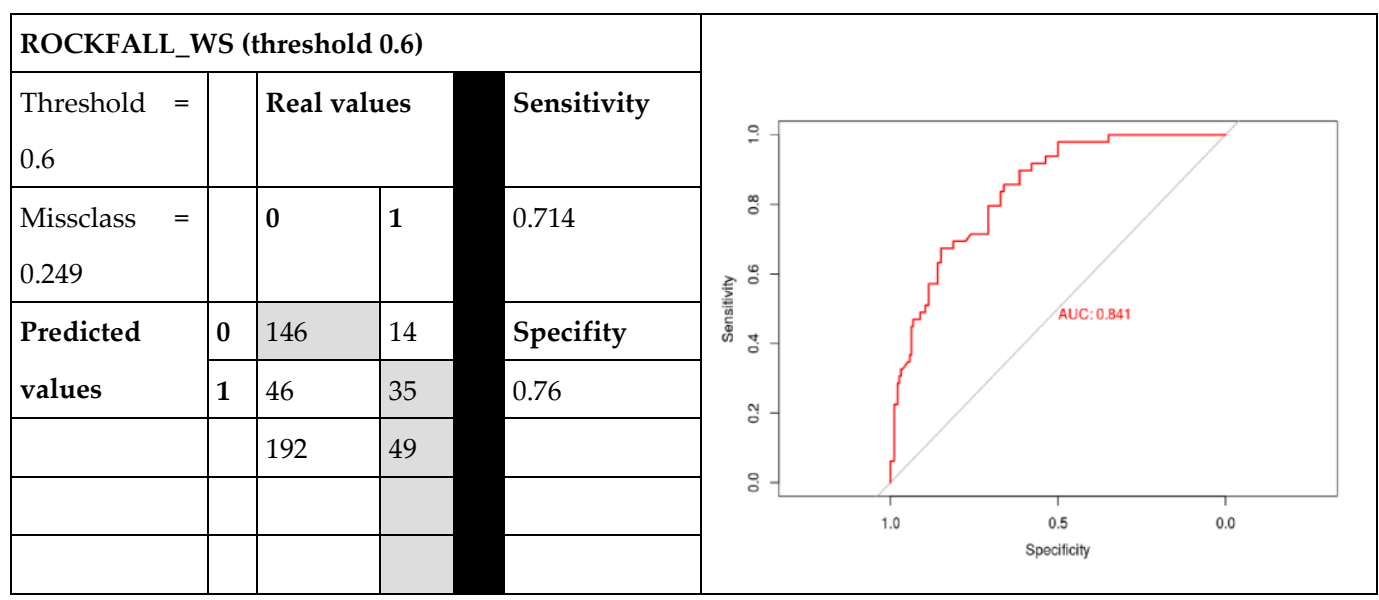

Figure 8. ROC curve and values of sensitivity and specificity of the predictive model (WS Model).

\subsection{Results of the BLR models (BLR.1 and BLR.2) Binomial logistic regression}

The results obtained for the two logistic regression models applied are summarized in the following tables, which show the results of the confusion matrix, the ROC curve, and the corresponding sensitivity and specificity values.

Table 7. Coefficients of the binomial logistic regression model with all variables (BRL.1).

\begin{tabular}{ccc}
\hline Variable & $\boldsymbol{\beta}$ estimated & $\mathbf{e}^{\boldsymbol{\beta}}$ \\
\hline (Intercept) & -7.65207 & 0,00047506 \\
\hline v01 & 4.55037 & 94,66742878 \\
v02 & 0.07575 & 1,078692867 \\
v03 & 1.48053 & 4,395274559 \\
v04 & 0.11564 & 1,122591666 \\
v06 & 2.20463 & 9,0668966196 \\
v10 & 1.21721 & 3,377750651 \\
\hline
\end{tabular}

ROCKFALL_K10 (threshold 0.25) 


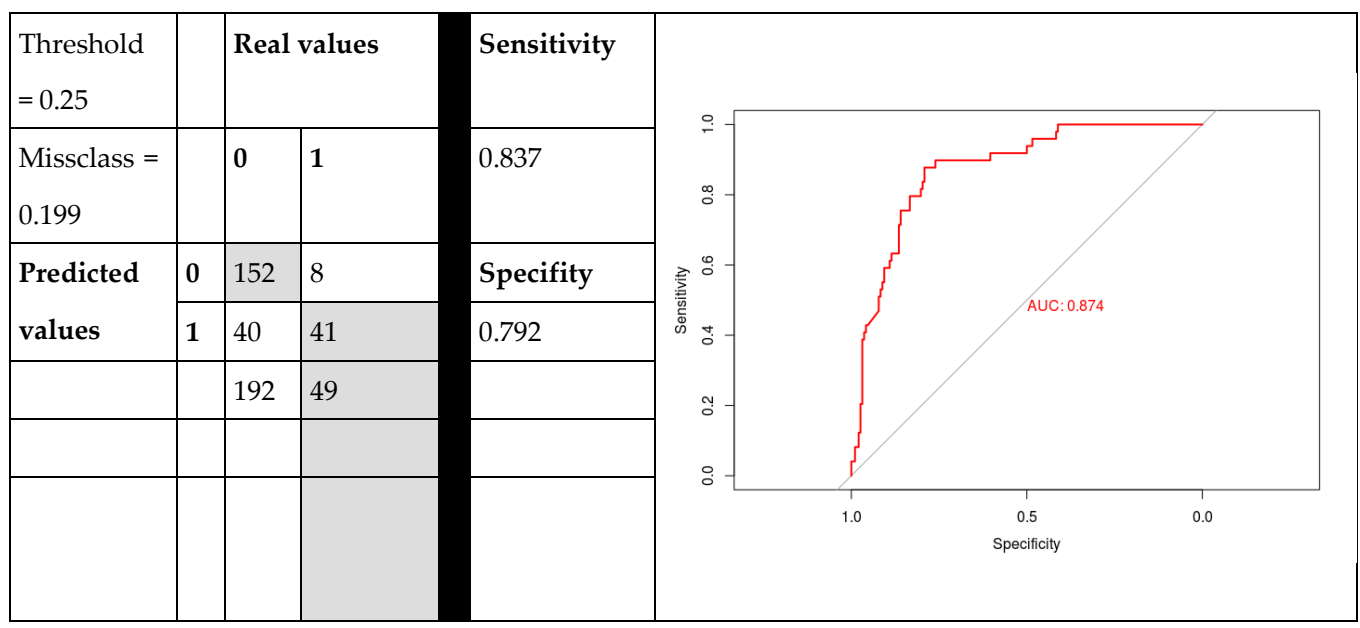

Figure 9. ROC curve and predictive validity indicators for the BLR.1 predictive model (logistic regression with all the variables). A probability threshold of 0.25 is considered to classify a slope as falling.

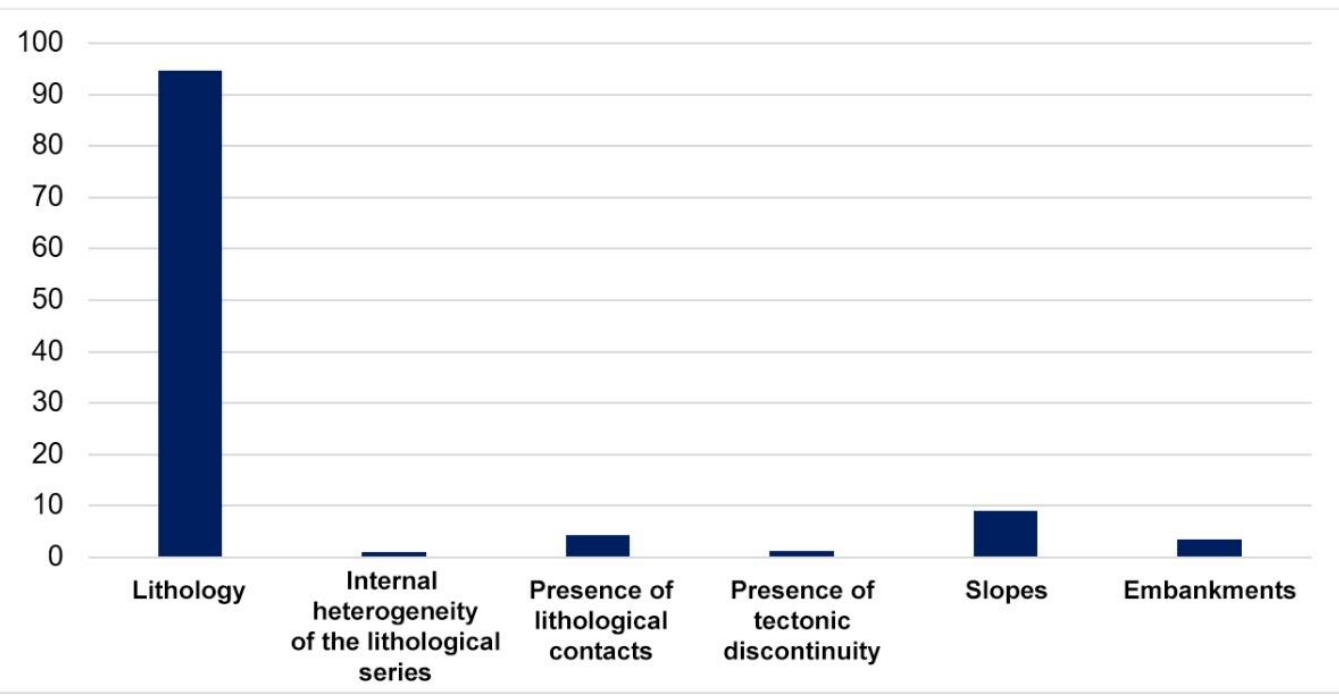

Figure 10. Coefficients obtained for the variables according to the BLR.1 predictive model (logistic regression with all the variables).

Table 8. Coefficients of the binomial logistic regression model with a reduced group of variables (BRL.2).

\begin{tabular}{ccc}
\hline Variable & $\boldsymbol{\beta}$ estimated & $\mathbf{e}^{\boldsymbol{\beta}}$ \\
\hline (Intercept) & -7.7109 & 0,000447918 \\
\hline v01 & 4.6998 & 109,9251852 \\
v03 & 1.5439 & 4,682817693 \\
v06 & 2.2040 & 9,06118585 \\
v10 & 1.1911 & 3,290698986 \\
\hline
\end{tabular}




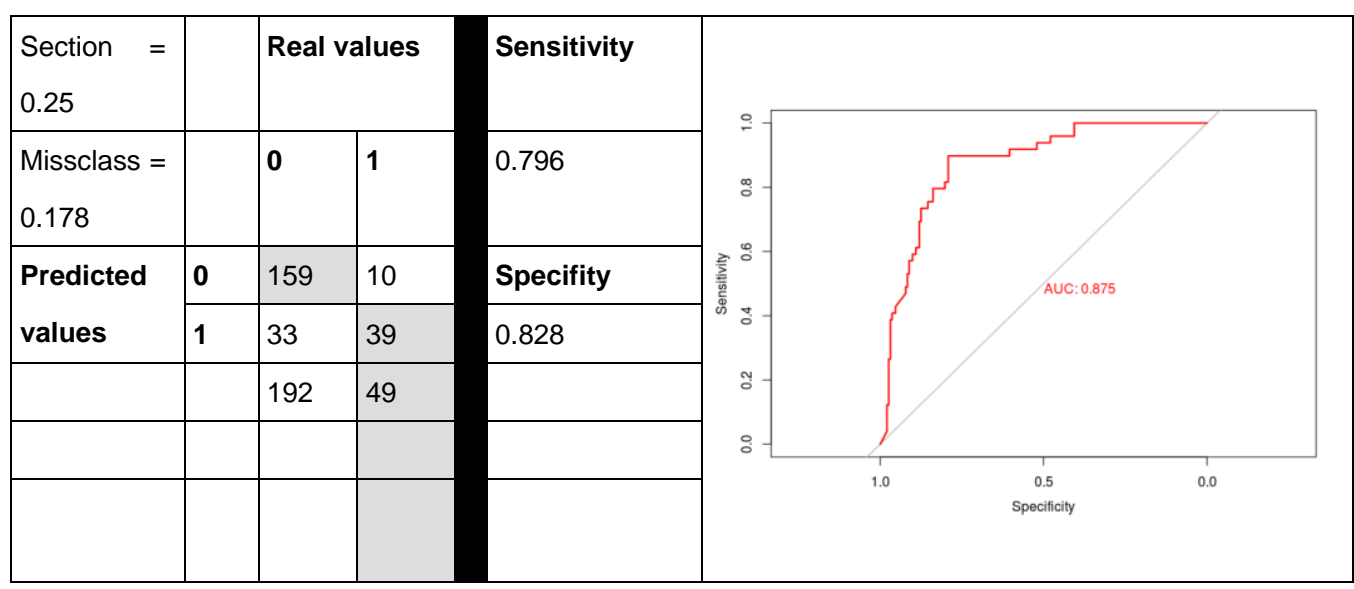

Figure 11. ROC curve and predictive validity indicators for the BLR.2 predictive model (logistic regression with a selection of the most significant variables). A probability threshold of 0.25 is considered to classify a slope as falling.

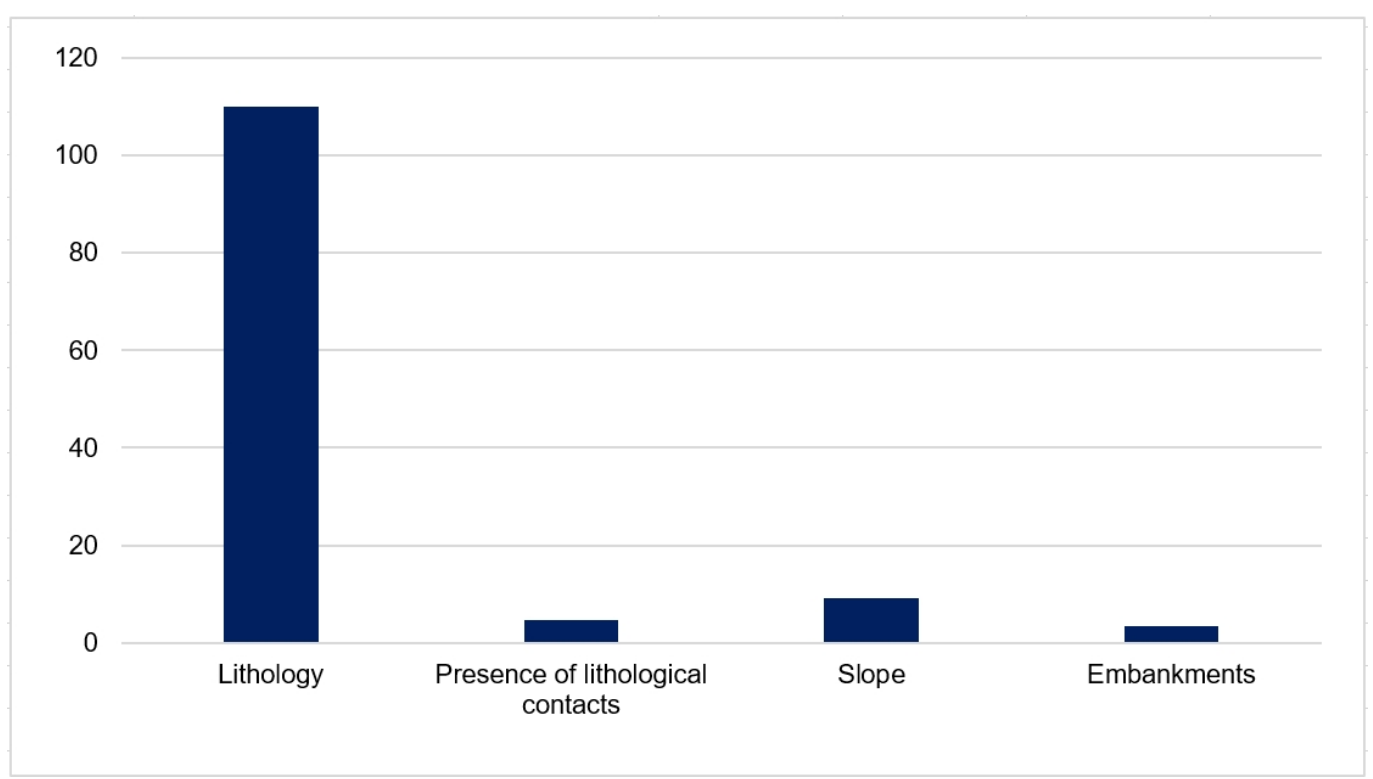

Figure 12. Coefficients obtained for the variables according to the BLR.2 predictive model (logistic regression including the variables with $\mathrm{p}<0.05)$.

As can be seen, the two regression models applied (BLR.1, using all the variables, or BLR.2, with the selection of those with the best statistical significance) offer very similar results, with a slight improvement in the AUC of the model, which uses a selection of variables. In both cases, this indicator presents values that prove the very good predictive capacity of the model (AUC $=0.87$ ), comparable to those obtained by logistic regressions applied by other authors such as [40], [41], [72], which are around 0.8. For the specific case of susceptibility to rockslide, [45] provided an AUC of 0.7 , and [73] a ROC index of $98.5 \%$.

The results for both models are also equivalent in terms of sensitivity and specificity, and BLR.1 shows a slightly better result in the ratio of correct positives compared to BLR.2 (sensitivity $=0.83$, and 0.79 , respectively), which allows to deduce that the reduction of the number of variables does not improve the predictive capacity of the model. The global values of the model clearly describe it as a solid proposal, with high predictability. [74], from the same logistic regression method, obtained AUC values of 0.9 , rated by the authors as excellent. They also gave a lower AUC to the capacity of correct prediction of the susceptibility map of the ELSUS 1000 program (0.6), and the one carried out by the Government of Gipuzkoa, with an AUC of 0.7.

Regarding the influence of each variable in slope instability, the same trend is observed in the two regression models applied. The influence of the variable lithology is 
much greater than the others: the normalized coefficient value practically multiplies by 10 the value of the next ranking variable. The second variable is the percentage of gradient, with a certain weight in determining the probability of falling of each slope. Finally, the variables presence of lithological discontinuity and presence of artificial cuts have little significance. The remaining variables have coefficients with low weight or low statistical significance. It is worthy to note the very high impact of the lithology in the instability process that has been observed in this study, since even it is very logical at the theoretical level, it cannot always be verified in statistical analyses, due to the categorical nature of the variable, which hinders the association with other causative variables. Usually, this variable is introduced in the analysis by assigning a score based on a susceptibility ranking, which generates subjectivity errors. In other cases, as suggested by [44], the susceptibility value of the lithology is obtained from the density of movement sites observed in each type of material, which, in our opinion, forces in a directed way the coincidence with the dependent variable, also constructed through the inventory of movements.

An example of the cartographic results of the application of the BLR.1 model are shown in Figure 13.

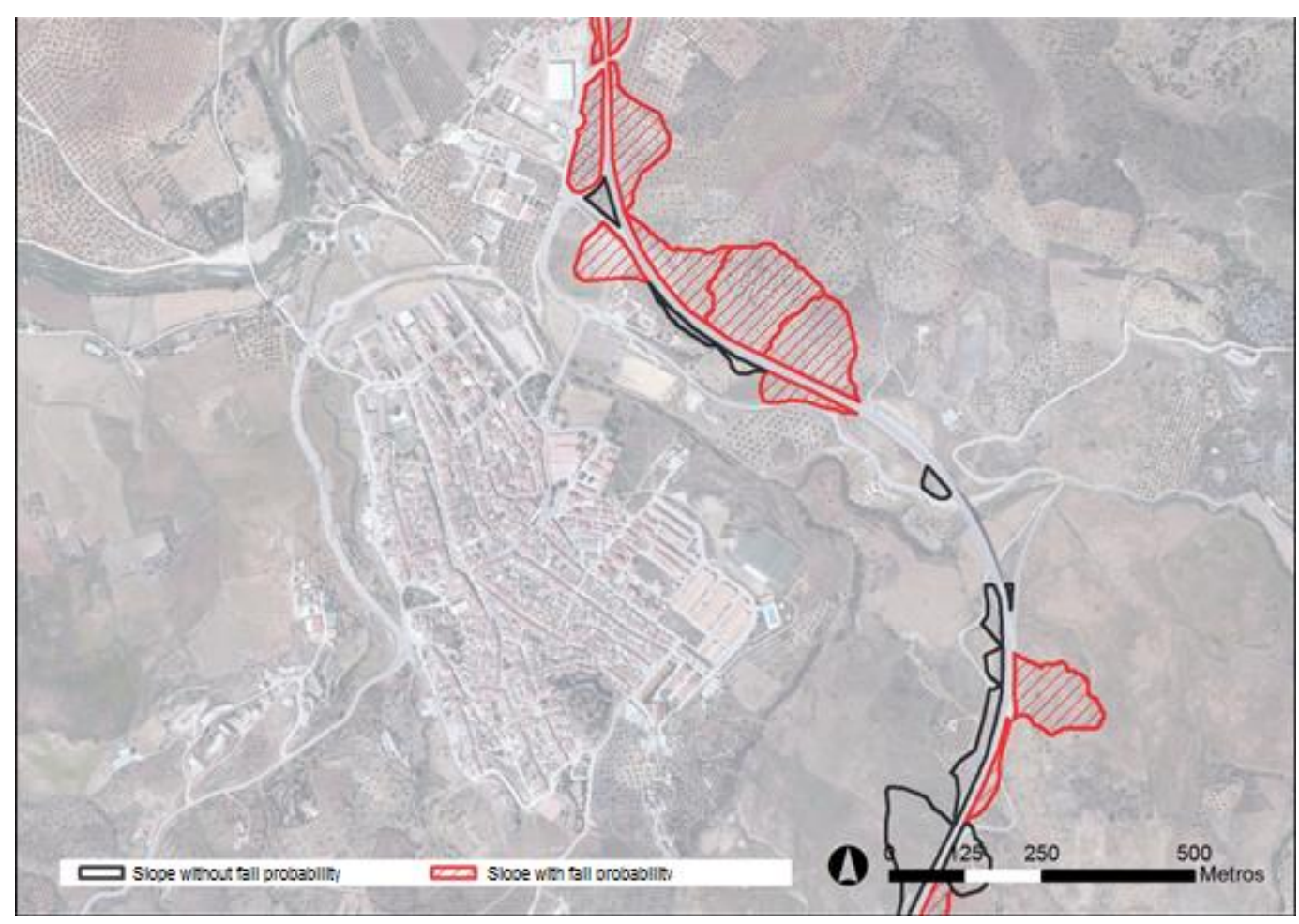

Figure 13. Susceptibility to falling slopes according to the BLR.1 predictive model (logistic regression with all the variables).

The cartographic results of the application of the BLR.2 model are shown in Figure 14. 


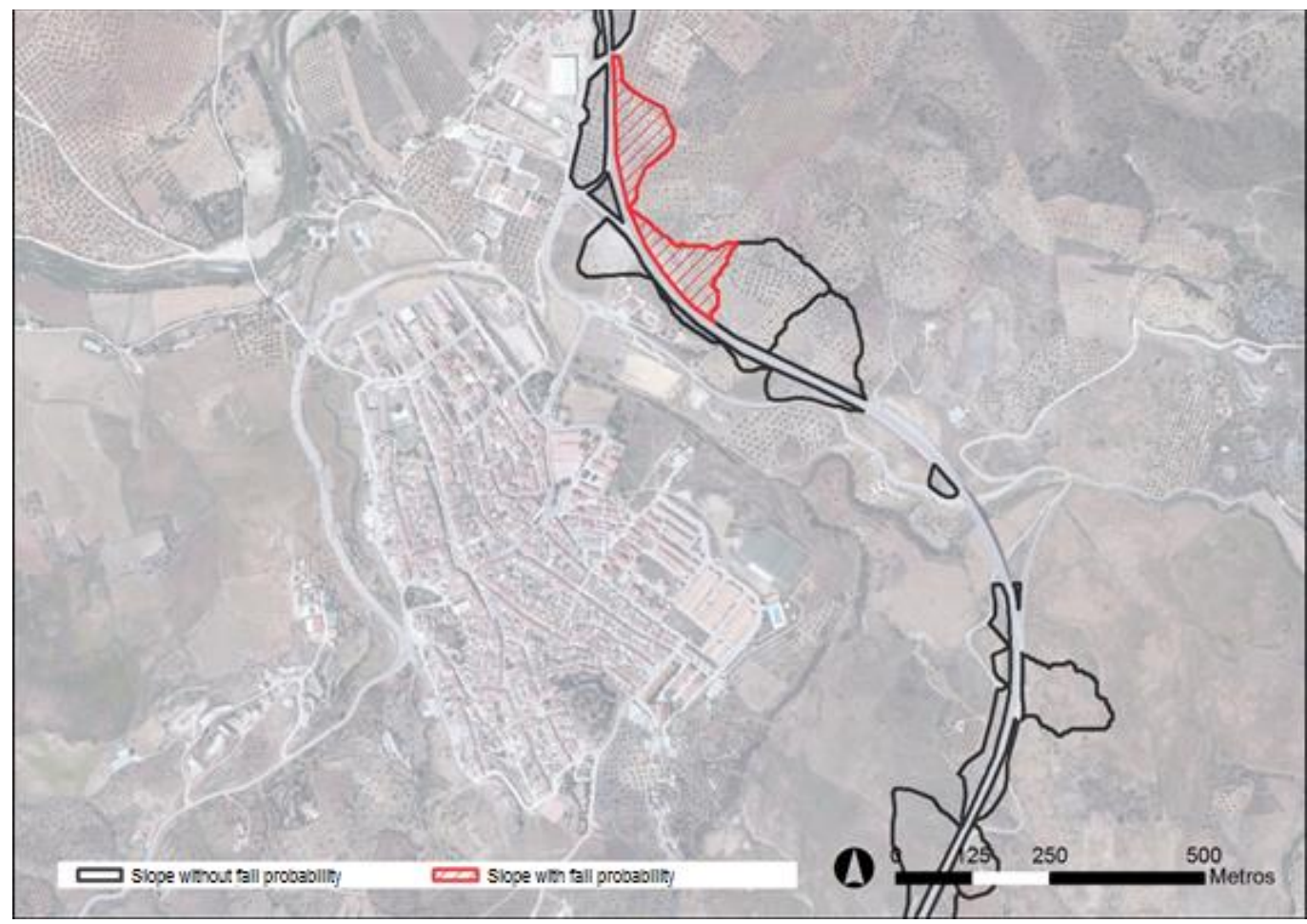

Figure 14. Susceptibility to falling slopes according to the BLR.2 predictive model (logistic regression with all the variables).

3.3. Comparison of the results obtained by the two methodologies used. WS model (frequency) and BLR.1 and BLR.2 models (logistic regression)

As shown in Figure 15., the results obtained for the two types of models that have been developed (based on frequency and logistic regression respectively), show high representative values, with very similar morphology and gradient of the ROC curve, and practically equivalent AUC ( 0.84 for the WS model, and 0.87 for the BLR. 1 and BLR.2 models). The proximity of the results shows, on the one hand, the validity of the predictive capacity of the models, and, on the other, it confirms the validity of the WS model, developed through a simpler methodological process, and with less complex statistical support. However, it has shown a degree of efficacy equivalent to more sophisticated methodological procedures.
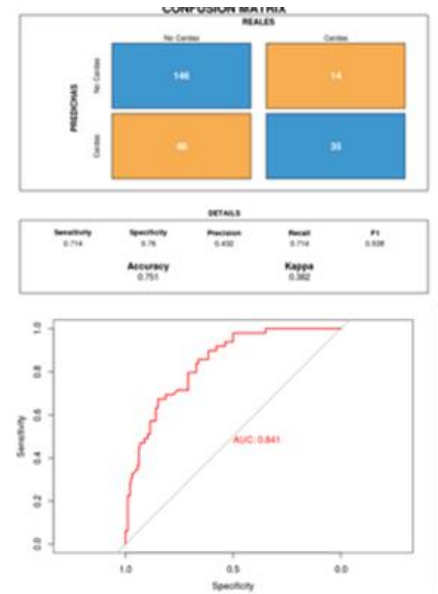
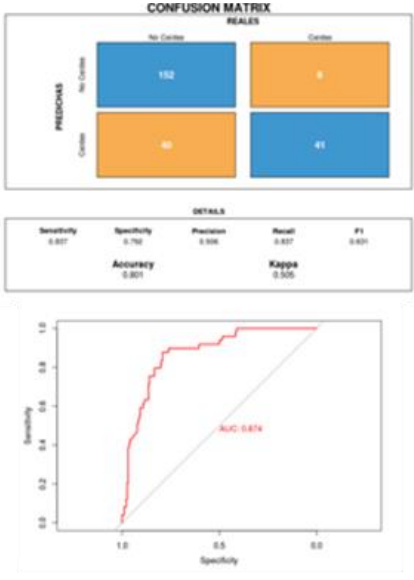
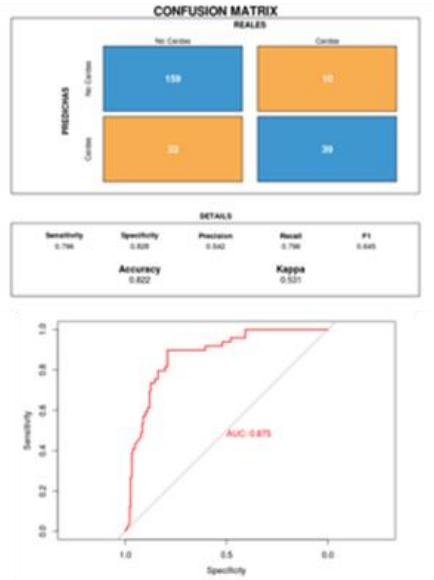

Figure 15. Comparison of the three models. From left to right: weighted sum WS, binomial logistic regression with all the variables, binomial logistic regression discarding variables with little significance $(\mathrm{p}>0.05)$ 
Regarding the identification of the most influential predictor variables in the creation of slope instability, both models coincide in two essential aspects: to highlight the importance of the lithology in the genesis of instability, followed by the gradient and, secondly, they also show the importance of an unnatural variable, such as the presence of artificial embankment, in the genesis of rockfall on slopes adjacent to roads.

\section{Conclusions}

The surrounding area of road infrastructures presents a degree of alteration by anthropic processes that strongly determines the dynamics of gravitational processes. To analyze the susceptibility to land mobilization on the slopes adjacent to road infrastructures requires a treatment of causative factors adapted to the specific characteristics of the environment. The approach used in this work has sought to collect these particularities and brings together ad hoc natural and anthropic factors as constrains of mobilization.

The disparate nature of the conditioning and activating factors of the mobilization, and its different expression in statistical terms, makes it difficult to use parametric statistics and linear correlation techniques as an instrument for the deduction of interchangeable relationships. To address this problem, complementary prediction strategies have been successfully addressed at work. First, as an alternative analysis strategy, a procedure based on the spatial coincidence of the most negative values of each predisposing factor with the effective occurrence of slope mobilization (WS predictive model) has been used. This procedure has allowed us to establish the relative importance of each determining factor in the final generation of the susceptibility to mobilization through a simple but effective process. After the application of the predictive model, the results obtained certify a high degree of coincidence between the tendency of susceptibility foreseen by the model, and the effective presence of empirical signs of mobilization on the slopes. The gradient of the ROC curve and the AUC parameter have proven the effectiveness of this model for the creation of cartographies of susceptibility to rockfalls. Secondly, a binomial logistic regression has been applied to obtain the BLR.1 and BLR.2 models, whose confidence indicators also showed a very good capacity of the equation to estimate the probability of landslides. The results of both models show the preponderant importance of lithology in the production of rockfalls, followed, at a considerable distance, by the gradient variable. The application of logistic regression has enabled the analysis with variables of different nature and statistical expression (continuous or categorical, and with or without normal distribution), so it is ideal for the case of study, in which they are linked as variable causative factors of low variability, or even dichotomous character, along with other discrete and wide variability. It must be added that the binomial logistic regression with selected variables (BLR.2), gets good predictions using only 4 variables, which allows to simplify the study processes in other cases. v02 and v04 are discarded due to low significance; this means that there is no significant causality regarding the increased probability of falls.

It is interesting to observe how in the two predictive models obtained, the importance in the genesis of the rockfalls of an unnatural variable, such as the presence of artificial embankment, is indicated. This fact points out the convenience of studying mass movements that occur in natural environments and have their own functional dynamics, as distinct processes with respect to those that take place in anthropized environments. In this latter case, it is necessary to analyze in a specific way factors that determine nonnatural mobilization, usually not considered in the predictive cartographies, but which, however, can take a leading role in the instability process. The results also speak about the relative effectiveness of the construction engineering models in the designing of road infrastructures, since it is confirmed that there are abundant cases of slopes with rockfalls associated with their construction. It is necessary, therefore, to apply a less sectoral approach to the prediction procedures, which includes a vision of road infrastructures as a mixed nature space, in which natural and artificial processes interact in the genesis of instability.

Author Contributions: Perles: designed the methodology and the conceptual approach; analyzed the data, writing the manuscript and revised the manuscript. Pardo: designed and applied the 
statistical methodology, and interpretation of results and discussion; Sortino: was involved in data processing, GIS application, interpretation of results and discussion; Reyes: GIS application and design maps, formatted and edited the text and graphics; Puglisi. compiled previous and current research, collaborated to design the methods, and approved the final version of the manuscript.

\begin{abstract}
Acknowledgments: This study is framed within the Research Project: “Development of an applied methodology for the detection of conflict points in the road infrastructures of Andalusian peri-urban areas in the face of episodes of activation of synergistic risks associated with torrential rains". Financing: Department of Infrastructure and Housing of the Junta de Andalucía, and Agency for Public Works (J.A). (Code G-GI 3000 / IDI).
\end{abstract}

\title{
References
}

1. Luce, C.H. \& Wemple, B.C. Introduction to special issue on hydrologic and geomorphic effects of forest roads. Earth Surface Processes and Landforms 2001, 26, 111-113.

2. Perles Roselló, M.J. \& Cantarero Prados, F. Problemas y retos en el análisis de los riesgos múltiples del territorio: propuestas metodológicas para la elaboración de cartografías multi-peligros. Boletín de la Asociación de Geógrafos Españoles 2010, 52, $245-271$.

3. Corominas, J.; Ibarbia, I.; Luzuriaga, S.; Navarro, J.A.; Jujo, I.; Jurnet, C.; Hurlimann, M. Rockfall and debris flow hazard assessment of the coastal road of Gipuzkoa (Northern Spain). In Landslides Science and Practice, Margottini, C., Canuti, P., Sassa, K. (eds.), Risk Assessment, Management and Mitigation. Ed. Springer. Germany. 2013; vol. 6.

4. Turconi, L.; Faccini, F.; Marchese, A.; Paliaga, G.; Casazza, M.; Vojinovic, Z.; Luino, F. Implementation of Nature-Based Solutions for Hydro-Meteorological Risk Reduction in Small Mediterranean Catchments: The Case of Portofino Natural Regional Park, Italy. Sustainability 2020, 12, 1240.

5. Giordan, D.; Wrzesniak, A.; Allasia, P. The Importance of a Dedicated Monitoring Solution and Communication Strategy for an Effective Management of Complex Active Landslides in Urbanized Areas. Sustainability 2019, 11, 946.

6. Bezerra, L.; Neto, O.F.; Santos, O., Jr.; Mickovski, S. Landslide Risk Mapping in an Urban Area of the City of Natal, Brazil. Sustainability 2020, 12, 9601.

7. Perles Roselló, M.J. \& Mérida Rodríguez M.F. Patrón territorial y conformación del riesgo en espacios periurbanos. El caso de la periferia este de la ciudad de Málaga. Scripta Nova 2010, XIV.

8. Perles Roselló, M.J.; Mérida Rodríguez, M.F.; Blanco Sepúlveda, R. Urbanización infraestructuras y riesgos naturales en la periferia montañosa de la ciudad de Málaga. El caso del Monte San Antón. Baética 1998, 20, 129-158.

9. Youssef, A.M.; Pradhan, B.; Hassan, A.M. Flash flood risk estimation along the St. Katherine Road, southern Sinai, Egypt using GIS based morphometry and satellite imagery. Environmental Earth Sciences 2011, 62(3), 611-623.

10. Michoud, C.; Derron, M.-H.; Horton, P.; Jaboyedoff, M.; Baillifard, F.-J.; Loye, A.; Nicolet, P.; Pedrazzini, A.; Queyrel, A. Rockfall hazard and risk assessments along roads at a regional scale: example in Swiss Alps. Nat. Hazards Earth Syst. Sci. 2012, 12, 615629, https://doi.org/10.5194/nhess-12-615-2012.

11. Fell, R.; Corominas, J.; Bonnard, C.; Cascini, L.; Leroi, E.; Savage, W.Z. Guidelines for landslide susceptibility, hazard and risk zoning for land-use planning. Eng Geol 2008, 102, 99-111.

12. Günther, A.; Van Den Eeckhaut, M.; Reichenbach, P.; Hervás, J.; Malet, J.-P.; Foster, C.; Guzzetti, F. New developments in harmonized landslide susceptibility mapping over Europe in the framework of the European Soil Thematic Strategy. In Proceedings of the Second World Landslide Forum, 3- 7 October 2011, Rome, Italy; Margottini, C., Canuti, P. Sassa, K. (Eds): Springer, 2011.

13. García-Ruiz, J.M.; Beguería, S.; Lorente, A.; Martí, C. Comparing debris flow relationships in the Alps and in the Pyrenees. Instituto Pirenaico de Ecología: Zaragoza, Spain, 2002.

14. Rickenmann, D. Empirical relationship for debris flow. Kluwer Academic Publishers: Amsterdam, Netherlands, 1999.

15. Puglisi, C.; Falconi, L.; Lentini, A.; Leoni, G.; Prada, C.R. Debris flow risk assessment in the Aguas Calientes Village (Cusco, Perù). In Landslide science and practice. Margottini C, Canuti P, Sassa K (eds): Springer: Berlin, 2013, 519-526.

16. Guzzetti, F.; Carrara, A.; Cardinali, M.; Reichenbach, P. Landslide hazard evaluation: a review of current techniques and their application in a multi-scale study, Central Italy. Geomorphology 1999, 31, 181-216.

17. Ardizzone, E.; Cardinali, M.; Carrara, A.; Guzzetti, F.; Reichenbach, P. Impact of mapping errors on the reliability of landslide hazard maps. Nat Hazards Earth Syst Sci 1999, 2, 3-14.

18. Chacón, J. \& Corominas, J. Landslides and GIS. Special Issue. Natural Hazards 2003, 30:3, $263-512$.

19. González-Jiménez, A.; Carrasco, R.M.; Ayala Carcedo, F.J.; Pedraza, J.; Martín-Duque, J.F.; Sanz, M.A.; y Bodoque, J.M.; Sanz, $\mathrm{M}$. El análisis de la susceptibilidad en la prevención de los movimientos de ladera: un análisis comparativo de las metodologías aplicadas al Valle del Jerte (Sistema Central español). In Riesgos naturales y desarrollo sostenible. Impacto, predicción y mitigación. IGME. Serie Medio Ambiente y Riesgos Geológicos (10). Ayala Carcedo J., Olcina Cantos, J., Laín Huerta, L., Gonzáles Jiménez, A. IGME: Madrid, Spain, 2006.

20. Felicísimo, A.; Cuartero, A.; Remondo, R.; Quirós, E. Mapping landslide susceptibility with logistic regression, multiple adaptive regression splines, classification and regression trees, and maximum entropy methods: a comparative study. Landslides 2013, 10 (2), 175-189. 
21. Razavizadeh, S.; Solaimani, K.; Massironi, M.; Kavian, A. Mapping landslide susceptibility with frequency ratio, statistical index, and weights of evidence models: a case study in northern Iran. Environ Earth Sci 2017, 76, 499. DOI 10.1007/s12665-0176839-7

22. Selby, M. J. A rock mass strength classification for geomorphic purposes: with tests from Antarctica and New Zealand. Geomorph 1980, 24(1), 31-51.

23. Romana, M. El papel de las clasificaciones geomecánicas en el estudio de la estabilidad de taludes. In IV Simposio nacional sobre taludes y laderas inestables, Granada, Spain, 1997, vol. III, 955-1011.

24. Serón, J. B.; Romana, M.; Montalar, E.; Cruzado, J. M.; Denia, J. L. Aplicación de la clasificación geomecánica SMR mediante un Sistema de Información Geográfica (SIG). V Simposio Nacional Taludes y Laderas Inestables, Madrid, Spain, 2001, vol. I, 405-416.

25. Hantz, D.; Corominas, J.; Crosta, G.B.; Jaboyedoff, M. Definitions and Concepts for Quantitative Rockfall Hazard and Risk Analysis. Geosciences 2021, 11, 158. https://doi.org/10.3390/ Geosciences 11040158

26. Corominas, J. \& Mavrouli, O. 2013. Estimation quantitative du risque (QRA) pour les bâtiments lié aux (C) European Union, Société Vaudoise des Sciences Naturelles (SVSN): Switzerland, 2013.

27. Amadesi E.; Vianello G.; Bonfatti G.; Pignone R.; Preti D. Guida alla realizzazione di una carta della stabilità dei versanti. Pitagora Editrice: Bologna, Italy, 1977, 72.

28. Chacón, J.; Irigaray, C.; Fernández del Castillo, T.; El Hamdouni, R. Susceptibilidad a los movimientos de ladera en el sector central de la Cordillera Bética. In Mapas de susceptibilidad a los movimientos de ladera con técnicas SIG. Fundamentos y Aplicaciones en España. Ayala-Carcedo, F.J. \& Corominas, J. (eds.). I.G.M.E, Serie Medio Ambiente №4: Madrid, Spain. 2003.

29. Sortino Barrionuevo, J.F; Mérida Rodríguez, M.F.; Perles Roselló, M.J. Susceptibilidad de movimientos en masa en infraestructuras viarias. Aplicación a un tramo de la autovía A-7 (circunvalación de Málaga). In Comprendiendo el relieve: del pasado al futuro. Actas de la XIV Reunión Nacional de Geomorfología. Durán, J.J., Montes, M., Robador, A., Salazar, A. (Eds.). IGME: Madrid, Spain, 2016.

30. Cardinali, M.; Reichenbach, P.; Guzzetti, F.; Ardizzone, F.; Antonini, G.; Galli, M.; Cacciano, M.; Castellani, M.; Salvatti, P. A geomorphological approach to the estimation of landslide hazards and risks in Umbria, Central Italy. Natural Hazards and earth System Sciences 2002, 2, 57-72.

31. Montgomery, D.R. \& Dietrich, W.E. A physically based model for the topographic control on shallow landsliding. Water Resour. Res. 1994, 30, 1153-1171.

32. Dietrich, W.E. \& Montgomery, D.R. Shalstab: a digital terrain model for mappingshallow landslide potential. Berkeley: California, United States, 1998.

33. Carrasco, R.M.; Pedraza, J.; Martín Duque, J.F.; Mattera, M.; Sanz M.A.; Bodoque, J.M.; Diez Herrero, A. Cartografía de zonas de susceptibilidad o propensión a los movimientos en masa en el Valle del Jerte (Sistema Central Español). In Mapas de susceptibilidad a los movimientos de ladera con técnicas SIG. Ayala-Carcedo, F. J. \& Corominas, J. (eds). IGME: Madrid, Spain, 2003. Serie: Medio Ambiente, 4, 133-153.

34. Carrara, A. A multivariate model for landslide hazard evaluation. Mathematical Geology 1983, 15, 403-426.

35. Carrara, A. Multivariate models for landslide hazard evaluation. A "Black Box" approach. Workshop on Natural Disasters in European Mediterranean Countries. Perugia, Italy, 1988, 205-224.

36. Carrara, A.; Cardinali, M.; Detti, R.; Guzzetti, F.; Pasqui, V.; Reichenbach, P. GIS techniques and statistical models in evaluating landslide hazard. Earth Surf Process Landf 1991, 16(5), 427-445. doi: 10.1002/esp.3290160505

37. Carrara, A.; Cardinali, M.; Guzzetti, F. Uncertainty in assessing landslide hazard and risk. ITC-Journal 1992, 2, $172-183$.

38. Carrara, A.; Cardinali, M.; Guzzetti, F.; Reichenbach, P. GIS technology in mapping landslide hazard. In Geographical Information Systems in assessing natural hazards. Carrara, A. \& Guzzetti, F. (eds). Kluwer Academic Publisher, Dordrecht, Netherlands. 1995, 135-175.

39. Clerici, A.; Perego, S.; Tellini, C.; Vescovi, P. A procedure for landslide susceptibility zonation by the conditional analysis method. Geomorphology 2002, 48, 349-364. doi:10.1016/S0169-555X (02)00079-X

40. Ayalew, L.; Yamagishi, H. The application of GIS-based logistic regression for landslide susceptibility mapping in the KakudaYahiko Mountains, Central Japan. Geomorphology 2005, 65, 15-31.

41. Bornaetxea, T.; Ormaetxea, O.; Antigüedad, I. Modelo de susceptibilidad de deslizamientos superficiales para la cuenca del río Oria (Gipuzkoa). Aplicación de la regresión logística y comparación de resultados con estudios precedentes. In Comprendiendo el relieve: del pasado al futuro. Actas de la XIV Reunión Nacional de Geomorfología. Durán, J.J.; Montes, M.; Robador, A.; Salazar, A. (eds.). Instituto Geológico y Minero de España: Málaga, Spain, 2016, 213-220.

42. Van Den Eeckhaut, M.; Vanwalleghem, T.; Poesen, J.; Govers, G.; Verstraeten, G. Prediction of landslide susceptibility using rare events logistic regression: a case-study in the Flemish Ardennes (Belgium). Geomorphology 2006, 76, $392-410$.

43. Yilmaz, I. Landslide susceptibility mapping using frequency ratio, logistic regression, artificial neural networks and their comparison: a case study from Kat landslides (Tokat-Turkey). Computers and Geosciences 2009, 35, 1125-1138.

44. Trigila, A.; Ladanza, C.; Esposito, C.; Scarascia-Mugnozza, G. Comparison of Logistic Regression and Random Forests techniques for shallow landslide susceptibility assessment in Giampilieri (NE Sicily, Italy). Geomorphology 2015, 249, 119-136.

45. Ataollah, S.; Lee, S.; Oh, H.; Kamran, C. A GIS-based logistic regression model in rock-fall susceptibility mapping along a mountainous road: Salavat Abad case study, Kurdistan, Iran. Nat Hazards 2012, 64, 1639-1656. DOI 10.1007/s11069-012-0321-3

46. Chau, K.; Tang, Y.; Wong, R. GIS-Based Rock-fall susceptibility map for Hong Kong. J Rock Mech Min Sci 2004, 41(3), 530-542.

47. Remondo, J.; Soto, J.; González-Díez, A.; Terán, J.R.D.; Cendrero, A. Human impact on geomorphic processes and hazards in mountain areas in northern Spain. Geomorphology 2005, 66, 69-84. 
48. San Millan, E.; González-Díez, A.; Fernández-Maroto, G. Influencia de las precipitaciones en los movimientos de ladera en Cantabria. In Comprendiendo el relieve: del pasado al futuro. Actas de la XIV Reunión Nacional de Geomorfología. Durán, J.J.; Montes, M.; Robador, A.; Salazar, A. (Eds.). SEG, Madrid, Spain. 2016.

49. Iriagaray, C. \& Chacón, J. Los movimientos de ladera en el sector de Colmenar (Málaga). Rev. Soc. Geol. España 1991, 4, 3003214.

50. Irigaray, C.; Chacón, J.; Romero, E. El deslizamiento de Ríogordo (Málaga). Geogaceta 1991, 10, 103-106.

51. IGME Atlas de riesgos naturales en la provincia de Granada. Instituto Geológico y Minero de España. Diputación de Granada, Granada, Spain. 2007.

52. Crozier M.J. Multiple occurrence regional landslide events. XII Reunión Nacional de Geomorfología, Santander, Spain. 2012.

53. Perles Roselló, M. J.; Pardo García, S. M.; Mérida Rodríguez, M.; Olcina Cantos, J. Methodology for the prediction of multiple risks points in road infrastructures after torrential episodes (road-risk). Boletín De La Asociación Española De Geografía $2019,80$. https://doi.org/10.21138/bage.2615

54. Kanungo, D.; Arora, M.; Sarkar, S.; Gupta, R.P. Landslide Susceptibility Zonation (LSZ) Mapping - A Review. Journal of South Asia Disaster Studies 2009, 2, 81-105.

55. Capitani M.; et al. The slope aspect: A predisposing factor for landsliding? Geoscience 2014, http://dx.doi.org/10.1016/j.crte.2013.11.002

56. Varnes, D.J. Slope movement types and processes. In Special Report 176: Landslides: Analysis and Control. Schuster, R. L. \& Krizek, R. J. Transportation and Road Research Board, National Academy of Science, Washington D. C., United States, 1978, 11-33.

57. Pedraza, J. Geomorfologia: principios, métodos y aplicaciones. Editorial Rueda, Madrid, Spain. 1996.

58. Reichenbach, P.; Rossi, M.; Malamud, B. D.; Mihir, M.; Guzzetti, F. A review of statistically-based landslide susceptibility models. Earth-Science Reviews 2018, 180, 60-91. https://doi.org/10.1016/j.earscirev.2018.03.001

59. Li, S.; Xu, Q.; Tang, M.; Li, H.; Yang, H.; Wei, Y. Centrifuge Modeling and the Analysis of Ancient Landslides Subjected to Reservoir Water Level Fluctuation. Sustainability 2020, 12, 2092.

60. Tien Bui, D.; Shirzadi, A.; Shahabi, H.; Geertsema, M.; Omidvar, E.; Clague, J.J.; Thai Pham, B.; Dou, J.; Talebpour Asl, D.; Bin Ahmad, B.; Lee, S. New Ensemble Models for Shallow Landslide Susceptibility Modeling in a Semi-Arid Watershed. Forests 2019, 10, 743 .

61. Li, C.; Tang, H.; Wang, Y. Study on the Deformation Mechanism of Reservoir Landslides Considering Rheological Properties of the Slip Zone Soil: A Case Study in the Three Gorges Reservoir Region. Sustainability 2020, 12, 6427.

62. Barredo, J.I.; Benavides, A.; Hervás, J.; Van Westen, C.J. Comparing heuristic landslide hazard assessment techniques using GIS in the Tirajana basin, Gran Canaria Island, Spain. JAG 2000, 2-1, 9-23.

63. Hosmer, J.R. \& Lemeshow, S., Applied logistic regression. John Wiley \& Sons, Oxford, United Kingdom. 2004.528 pp.

64. Wang, Q.; Wang, D.; Huang, Y.; Wang, Z.; Zhang, L.; Guo, Q.; Chen, W.; Chen, W.; Sang, M. Landslide Susceptibility Mapping Based on Selected Optimal Combination of Landslide Predisposing Factors in a Large Catchment. Sustainability 2015, 7, 1665316669.

65. Openshaw, S. The modifiable areal unit problem. CATMOG 38. GeoBooks, Norwich, England, 1984.

66. Dou, J.; Yunus, A.P.; Merghadi, A.; Shirzadi, A.; Nguyen, H.; Hussain, Y.; Avtar, R.; Chen, Y.; Pham, B.T.; Yamagishi, H.; Different sampling strategies for predicting landslide susceptibilities are deemed less consequential with deep learning. Sci Total Environ 2020, 720, 137320. doi: 10.1016/j.scitotenv.2020.137320.

67. Chang, KT.; Merghadi, A.; Yunus, A.P. et al. Evaluating scale effects of topographic variables in landslide susceptibility models using GIS-based machine learning techniques. Sci Rep 2019, 9, 12296. https://doi.org/10.1038/s41598-019-48773-2

68. Kouhartsiouk, D.; Perdikou, S. The application of DInSAR and Bayesian statistics for the assessment of landslide susceptibility. Nat Hazards 2021. https://doi.org/10.1007/s11069-020-04433-7

69. Selby, M.J. Hillslope Materials and Processes. Paperback Bunko, China. 1993.

70. Dorren, L. A review of rockfall mechanics and modelling approaches. Progress in Physical Geography 2003, $27(1), 69-87$.

71. Ferentinou, M.; Krebs, A.; Romer, C. Rockfall Susceptibility Analysis, the Case of the Access Road to the Giants Castle Nature Reserve, South Africa. ISRM Regional Symposium - EUROCK, 2015, Salzburg, Austria.

72. Wei Chen, H. \& Zhou, Z. A GIS-based comparative study of DempsterShafer, logistic regression and artificial neural network models for landslide susceptibility mapping. Geocarto International 2017, 32, 367-385.

73. Abedini, M.; Ghasemyan, B.; Rezaei Mogaddam, H. Susceptibility mapping in Bijar city, Kurdistan Province, Iran: a comparative study by logistic regression and AHP models. Environ Earth Sci 2017, 76, 308. DOI 10.1007/s12665-017-6502-3

74. Bornaetxea, T.; Ormaetxea, O.; Antigüedad, I. Modelo de susceptibilidad de deslizamientos superficiales para la cuenca del río Oria (Gipuzkoa). Aplicación de la regresión logística y comparación de resultados con estudios precedentes. In Comprendiendo el relieve: del pasado al futuro. Durán, J.J., Montes, M.; Robador, A.; Salazar, A. (eds.). Actas de la XIV Reunión Nacional de Geomorfología. Instituto Geológico y Minero de España, Málaga, Spain. 2016, 213-220. 2016. 